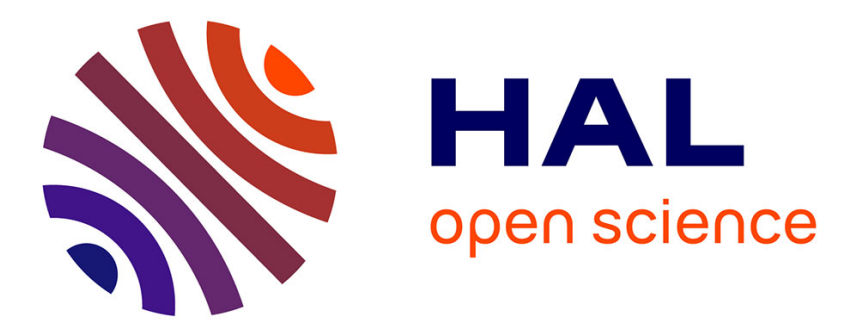

\title{
Investigation of the relationship between damping and mode-coupling patterns in case of brake squeal
}

\author{
Guillaume Fritz, Jean-Jacques Sinou, Jean-Marc Duffal, Louis Jezequel
}

\section{To cite this version:}

Guillaume Fritz, Jean-Jacques Sinou, Jean-Marc Duffal, Louis Jezequel. Investigation of the relationship between damping and mode-coupling patterns in case of brake squeal. Journal of Sound and Vibration, 2007, 307 (3-5), pp.591-609. 10.1016/j.jsv.2007.06.041 . hal-00225720

\section{HAL Id: hal-00225720 \\ https://hal.science/hal-00225720}

Submitted on 30 Jan 2008

HAL is a multi-disciplinary open access archive for the deposit and dissemination of scientific research documents, whether they are published or not. The documents may come from teaching and research institutions in France or abroad, or from public or private research centers.
L'archive ouverte pluridisciplinaire HAL, est destinée au dépôt et à la diffusion de documents scientifiques de niveau recherche, publiés ou non, émanant des établissements d'enseignement et de recherche français ou étrangers, des laboratoires publics ou privés. 
Journal home page: http://www.sciencedirect.com/science/journal/0022460X

Investigation of the relationship between damping and mode-coupling patterns in case of brake squeal Journal of Sound and Vibration, Volume 307, Issues 3-5, 6 November 2007, Pages 591-609 Guillaume Fritz, Jean-Jacques Sinou, Jean-Marc Duffal and Louis Jézéquel

\title{
Investigation of the relationship between damping and mode coupling patterns in case of brake squeal
}

\author{
Guillaume FRITZ ${ }^{1,2}$, Jean-Jacques SINOU ${ }^{2 *}$, Jean-Marc DUFFAL ${ }^{1}$, Louis JÉZÉQUEL ${ }^{2}$ \\ 1 - RENAULT, Research Department, TCR AVA 1 63, 1 avenue du Golf 78288 Guyancourt, France \\ 2 - Laboratoire de Tribologie et Dynamique des Systèmes UMR CNRS 5513, Ecole Centrale de Lyon, \\ 36 avenue Guy de Collongue, 69134 Ecully Cedex, France
}

\section{Abstract}

Brake squeal is a friction induced instability phenomenon that has to be addressed during the development process. The mechanism is considered a mode coupling phenomenon also referred to as coalescence. The system eigenvalues have been computed using a technique based on the finite element method. The coalescence patterns were then determined in relation to the friction coefficient. The effects of damping on the coalescence patterns have been investigated. If the two modes involved in the coalescence are equally damped, a "lowering effect" that tends to stabilize the system is observed. If the two modes are not equally damped, both "lowering" and "smoothing" effects occur. If the "smoothing effect" prevails, added damping may act in an unintuitive way by destabilizing the system. To further study this point, stability areas have been plotted and a metric is proposed to find the most stable configuration in terms of damping distribution. In the squeal frequency range, coalescence patterns often involve more than two modes. In this case, the effect of damping is far more complicated since several modes are coupled both in terms of friction and damping.

\section{Introduction}

Brake squeal is currently a key issue in brake development. This brake noise, with frequencies ranging from one to ten kiloHertz is quite annoying since levels of $110 \mathrm{~dB}$ may be reached. Development requires a great deal of experimental work based on a trial and error process. Moreover, it is all the more difficult to resolve given that brake power has increased over the past few years. Nevertheless, recent breakthroughs in numerical analyses have made it possible to tackle the issue upstream in the development process with promising results.

Brake squeal, which has been studied for years, is considered to be a friction induced instability phenomenon. Kinkaid, O'Reilly and Papadopoulos have proposed a review [1] that summarises the background and the main studies of brake squeal. Chen, Tan and Quaglia have published an overview [2] of recent breakthroughs in theoretical, experimental and numerical fields. As far as squeal modelling is concerned, 
two kinds of analyses may be performed: time or frequency domain analyses. These two procedures have specific advantages and drawbacks as mentioned by Mahajan, Hu and Zhang in [3]. The second procedure, called Complex Eigenvalue Analysis (CEA), has been the most used by researchers. It deals with computing the system eigenvalues, which prove to be complex valuated functions in the general case because friction causes the stiffness matrix to be asymmetric. The real and imaginary parts of the complex eigenvalues are respectively responsible for the stability and for the frequency of the corresponding modes. This method was first used on lumped models [1,4-8]. Then, improvements in computer systems have made it possible to perform analyses on finite element $(F E)$ models [9]. Since friction is the root cause of instability, some researchers have investigated the effect of the friction coefficient on complex eigenvalues [10-14]. They have highlighted the phenomenon referred to as mode-coupling, which shows the transition between the frictionless stable behaviour of the brake and its unstable behaviour with friction. Some researchers have focused on the deformed shapes of the modes. They have investigated the role of the frictionless real modes, of the components or of the entire system, on complex modes with friction. These two roles have been studied by Lee et al. in [12] using respectively the factors known as Component Modal Participation Factor and System Participation Factor.

Instabilities are understood through CEA as an equivalent negative damping. Therefore, the system damping is expected to have a significant effect on its stability. A brake system features several kinds of damping, such as structural damping, friction-induced damping and the damping effect of insulators. The effects of damping were first investigated on analytical and experimental analyses [15-21]. Nevertheless, taking damping into account in a whole brake FE model is far more complicated. Most researchers have therefore neglected damping, invoking the following rule of thumb: the undamped situation must be the worst. Some researchers have taken an overall damping value into account $[9,22,23]$. In most cases, a constant loss factor is applied to the entire frequency range. Other researchers have focused on an accurate modelling of damping sources: friction-induced damping [24-26] and shims [27-29].

This paper focuses on the effect of damping on the mode-coupling phenomenon involved in brake squeal. The study is based on the FE model of a commercial brake corner. Damping is taken into account in a modal way and a numerical method to extract the system damped eigenvalues is presented. Then, parametric studies are used to investigate the effect of damping on the mode-coupling phenomenon. Two cases are highlighted and specifically studied: the two mode coupling patterns and the coupling patterns that involve more than two modes.

\section{Numerical Method}

A commercial front brake has been modelled using the finite element method, as shown in Figure 1.

It leads to the general equation of motion 1.

$$
\mathbf{M u}+\mathbf{C} \dot{\mathbf{u}}+\mathbf{K u}=\mathbf{0}
$$

Where $\mathbf{M}, \mathbf{C}, \mathbf{K}$ are respectively the mass, damping and stiffness matrices. $\mathbf{u}$ is the displacement vector and dot denotes derivative with respect to time. Since contact and friction have been taken into account in the model, the stiffness matrix has specific properties given in Equation 2.

$$
\mathbf{K}=\mathbf{K}_{\text {Structure }}+\mu \mathbf{K}_{\text {Friction }}
$$




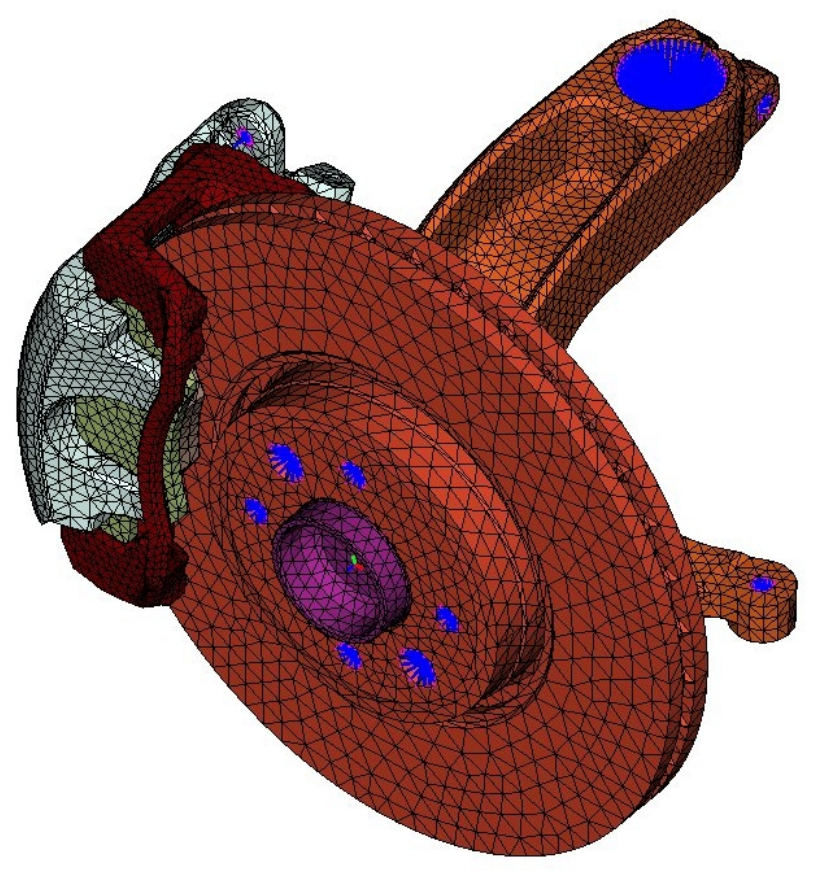

Figure 1: Finite element model

$\mathbf{K}_{\text {Structure }}$ is the structural stiffness matrix, which can be directly computed by FE solvers. This matrix includes the springs used to model contacts between components. $\mu$ is the friction coefficient and $\mathbf{K}_{\text {Friction }}$ is the asymmetrical friction induced stiffness matrix. The second term in Equation 2 may be obtained analytically by expanding the friction force as a function of the displacements of the contact nodes. This point, which will not be presented here for the sake of brevity, is based on the Coulomb law [30].

The undamped and frictionless case, defined in Equation 3, is noteworthy because it involves a symmetric stiffness matrix and therefore does not require a complex solver.

$$
\mathbf{M u}+\mathbf{K}_{\text {Structure }} \mathbf{u}=\mathbf{0}
$$

In this case, FE software is able to compute the frequencies $\omega$ and the modal basis $\Phi$ through a normal mode analysis. $\Phi$ gathers the first $n$ eigenvectors as columns, normalized with respect to the mass matrix. $n$ is related to the chosen modal truncation. $\Omega$ is defined in Equation 4 as the diagonal matrix gathering the frequencies.

$$
\Omega=\operatorname{diag}\left(\omega_{1} \cdots \omega_{n}\right)
$$

The displacement vector in Equation 1 can be expressed as a linear combination of the undamped and frictionless modes. This relationship is written in matrix form in Equation 5, with $\Upsilon$ the displacement coordinates in the undamped and frictionless modal basis. $\Upsilon$ may also be named modal participation vector (mpv).

$$
\mathbf{u}=\Phi \Upsilon
$$

Once left multiplied by $\Phi^{\mathrm{T}}$, transformed in the frequency domain and expanded using the orthogonality 
relations, Equation 1 can be rewritten as Equation 6.

$$
\left[\mathbf{I} s^{2}+\mathbf{D} s+\left(\boldsymbol{\Omega}^{2}+\mu \boldsymbol{\Lambda}_{\mathbf{f}}\right)\right] \Upsilon \mathbf{\Upsilon}=\mathbf{0}
$$

$\mathrm{D}$ and $\boldsymbol{\Lambda}_{\mathbf{f}}$ are respectively the projections of $\mathbf{C}$ and $\mathbf{K}_{\text {Friction }}$ on the undamped and frictionless modal basis. $\mathbf{I}$ is the identity matrix and $s$ is the Laplace parameter.

For a given $\mu$ and a given D, Equation 6 can be rewritten as a general eigenvalue problem involving the eigenvalue $s$ and the eigenvector $\Upsilon$. In the general case, both are complex valuated functions as shown in Equation 7.

$$
s=a+i b \quad \Upsilon=\Upsilon_{\text {real }}+i \Upsilon_{\text {imag }}
$$

Eigenvectors account for the mode deformed shapes and eigenvalues account for the mode time behaviours. The eigenvalue imaginary parts deal with mode frequencies, whereas the real parts deal with mode stability. A mode is stable if $a \leq 0$, and is otherwise unstable.

Let $\Gamma$ be a matrix in which the eigenvectors $\Upsilon$ are stored by columns. Equation 5 makes it possible to write $\Psi$, the modal deformed shapes with friction, as a function of the frictionless modal basis $\Phi$. $\Gamma$ is the modal participation matrix linking $\Psi$ and $\Phi$.

$$
\Psi=\Phi \Gamma
$$

From a practical point of view, the procedure can be summarised as follows. First, the normal modes of the frictionless and undamped model are computed by FEM. From the results, the terms of Equation 6 can be inferred. Then, the eigenvalues and the eigenvectors related to this equation are computed and analysed.

\section{Two mode coupling patterns}

\subsection{Undamped coupling patterns}

In the undamped case, where we assume that $\mathrm{D}$ is zero, the only remaining variable in Equation 6 is $\mu$. A parametric study has thus been performed with respect to this parameter. Figure 2 gathers curves describing the eigenvalue variability for 100 values of the friction coefficient. For the sake of clarity, this figure focuses on two modes chosen for their propensity to instability. Real parts have been normalized so that the largest value in figure 2 is one. Frequencies and friction values have been normalized with respect to a point which will be defined below.

Figure 2 displays the evolution of frequencies and real parts as a function of the friction coefficient. At $\mu=0$, the system features two separate modes in the frequency range, that will be referred to as $M 1$ and $M 2$ by increasing frequencies. These two modes are stable since their real parts are zero. The corresponding frictionless deformed shapes, which have been computed through a FE normal mode extraction, are shown in Figure 3. M1 consists of an in-phase bending of the knuckle mounts that drives the anchor bracket in a rigid body rocking mode. The calliper translates along its guiding pins. M2 features a knuckle twisting mode that makes the knuckle mounts move in anti-phase. Thus, the anchor twists and drives the calliper in rotation by means of the guiding pins. Meanwhile, the pads slip along the disc surface between the leading and trailing abutments. The coupling between $M 1$ and $M 2$ belongs to 
the general class of coupling between translation and rotation modes that is often encountered in analyses involving friction.

As the friction coefficient increases, Figure 2 shows that the real parts remain zero and that the frequencies tend to get closer. The two modes reach the same frequency at a point known as the "bifurcation point" (or "lock-in point"). This point, which occurs for a friction value of 0.34 , has been used as a reference to normalize frequency and friction values. After that point, the system behaviour is deeply altered. Indeed, the frequencies remain equal but the real parts become non zero and opposite. As mentioned in the previous section, this means that one of them is stable $(a<0)$ whereas the other one is unstable $(a>0)$.

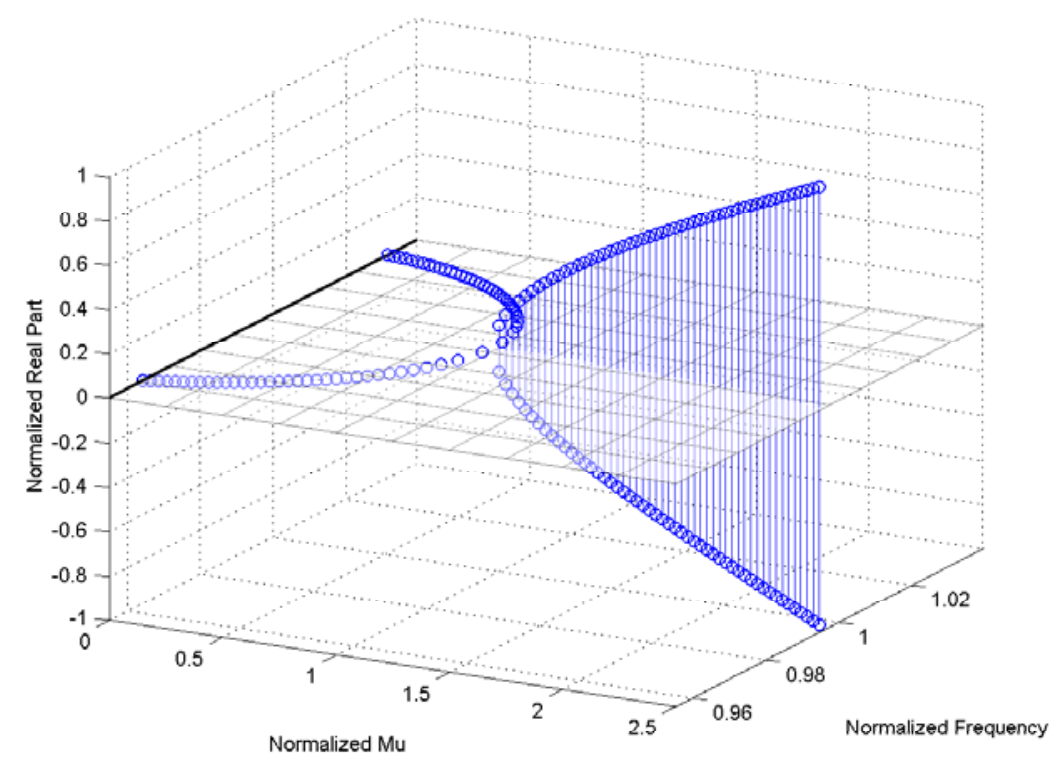

Figure 2: Undamped coalescence pattern

Having studied eigenvalue variability, we now focus on eigenvector variability as a function of the friction coefficient. The eigenvectors $\Upsilon$ are scaled so that the norm of each is 1 . The five most influential terms of the modal participation vectors corresponding to $M 1$ and $M 2$ are shown in Figure 4. The reference numbers in the key give the indices of the frictionless modes that participate in $M 1$ or $M 2$. 0 refers to the "current" mode ( $M 1$ or $M 2$ respectively), 1 to the "next" one and - 1 to the "previous" one, in the order of the frictionless frequency. Note that for the sake of clarity, only one point out of ten has been marked, but the curves have not been artificially smoothed. As expected, at $\mu=0, M 1$ is a real mode, where all the participation factors are zero except the one corresponding to $M 1_{\text {Frictionless }}$ which is 1 . As the friction coefficient increases, the influence on $M 1$ of $M 1_{\text {Frictionless }}$ decreases quickly whereas that of $M 2_{\text {Frictionless }}$ increases. Once the bifurcation point is reached (Normalized $\mathrm{Mu}=1$ ), the curves have slope-breaks and the mode becomes complex. For $M 2$, the influence of $M 2_{\text {Frictionless }}$ decreases slowly whereas that of $M 1_{\text {Frictionless }}$ increases as the friction coefficient increases from zero. At the bifurcation point, $M 1$ and $M 2$ have the same modal participation factors. This means that these two modes are the same. Beyond that point, the participation factors of the two modes remain equal in real parts and opposite in imaginary parts. This point is due to the fact that the eigenproblem defined in Equation 6 involves 


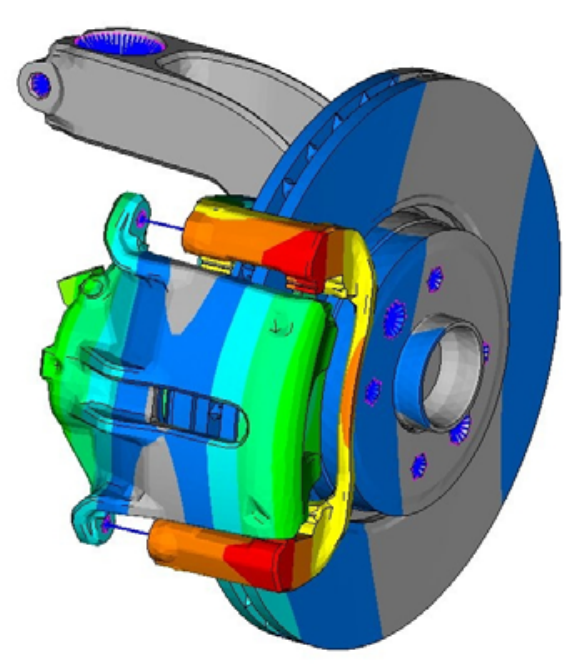

(a)

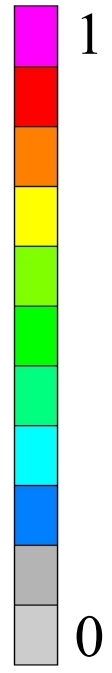

0

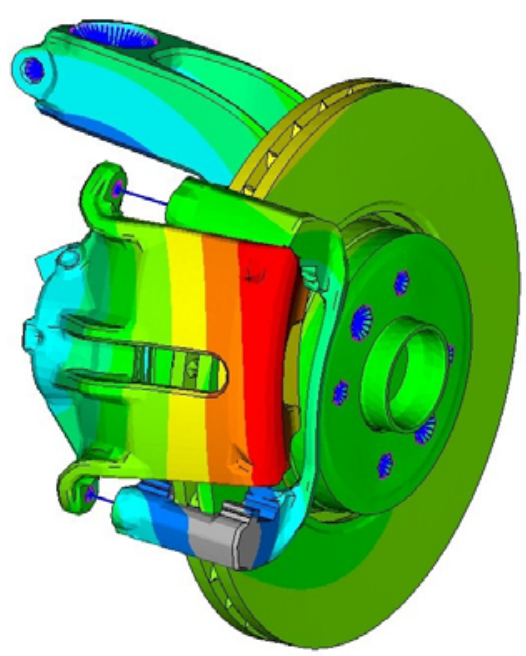

(b)

Figure 3: Undamped deformed shapes - (a) Mode $M 1_{\text {Frictionless }}$ - (b) Mode $M 2_{\text {Frictionless }}$

a real matrix. Assuming that the couple $(\lambda, X)$ is the complex eigenvalue and complex eigenvector of a real matrix $\mathbf{A}$. It can be proven that the complex conjugate couple, $(\bar{\lambda}, \bar{X})$, is also an eigenvalue and eigenvector of $\mathbf{A}$.

The bifurcation point is a singular point, at which the eigenvalues and the eigenvectors corresponding to the two modes are the same. Therefore, it is impossible to track the modes passing through the bifurcation point. After that point, the stable mode has thus been arbitrarily linked to $M 1$ and the unstable one to $M 2$. Beyond the coalescence point, the contribution of $M 1_{\text {Frictionless }}$ on the real parts decreases whereas its influence on the absolute value of the imaginary parts increases. Finally, $M 2_{\text {Frictionless }}$ has a very strong impact on the real parts and $M 1_{\text {Frictionless }}$ drives the imaginary parts of $M 1$ and $M 2$.

\subsection{Damped coupling patterns}

In this section, $\mathrm{D}$ is assumed to be:

$$
\mathbf{D}=\operatorname{diag}(0 \cdots 0, d 1, d 2,0 \cdots 0)
$$

So that only $M 1$ and $M 2$ are damped, respectively with $d 1$ and $d 2$.

The equally damped case, defined as $d 1=d 2=d$ has been studied first and the results are shown in Figure 5(a). The undamped case, which will be referred to as Case A, is compared with two equally damped cases, Case B and Case C, defined in Table 1. As previously explained by Hoffmann and Gaul [18], and by Sinou and Jézéquel [7], increasing the value of $d$ makes the eigenvalue real parts decrease, whereas the frequencies remain approximately constant. Indeed, in the complex plane, the eigenvalues are shifted towards the stable side. The eigenvalue real parts become positive for a higher value of the friction coefficient. Therefore, increasing $d$ increases the brake stability range.

The coupling patterns involved in the unequally damped cases are far more complicated, as illustrated in Figure 5. The undamped case, Case A, is compared with two unequally damped cases, Case D and Case 

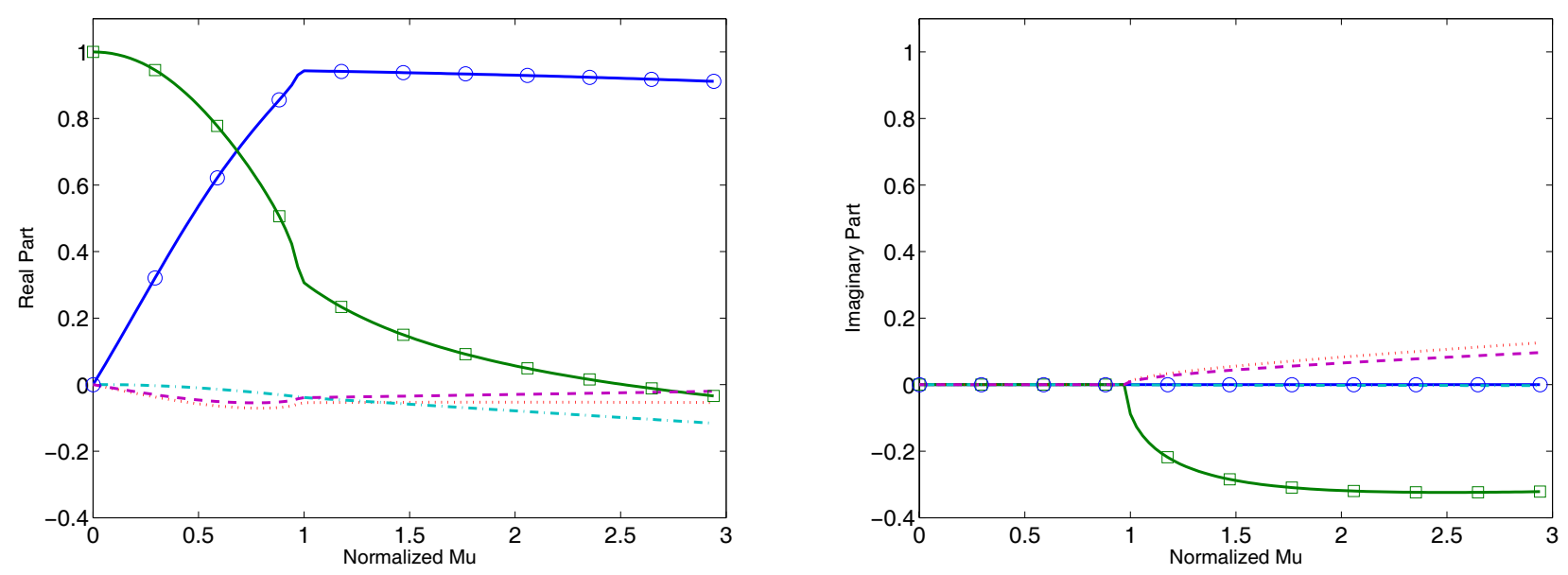

(a)

legend :
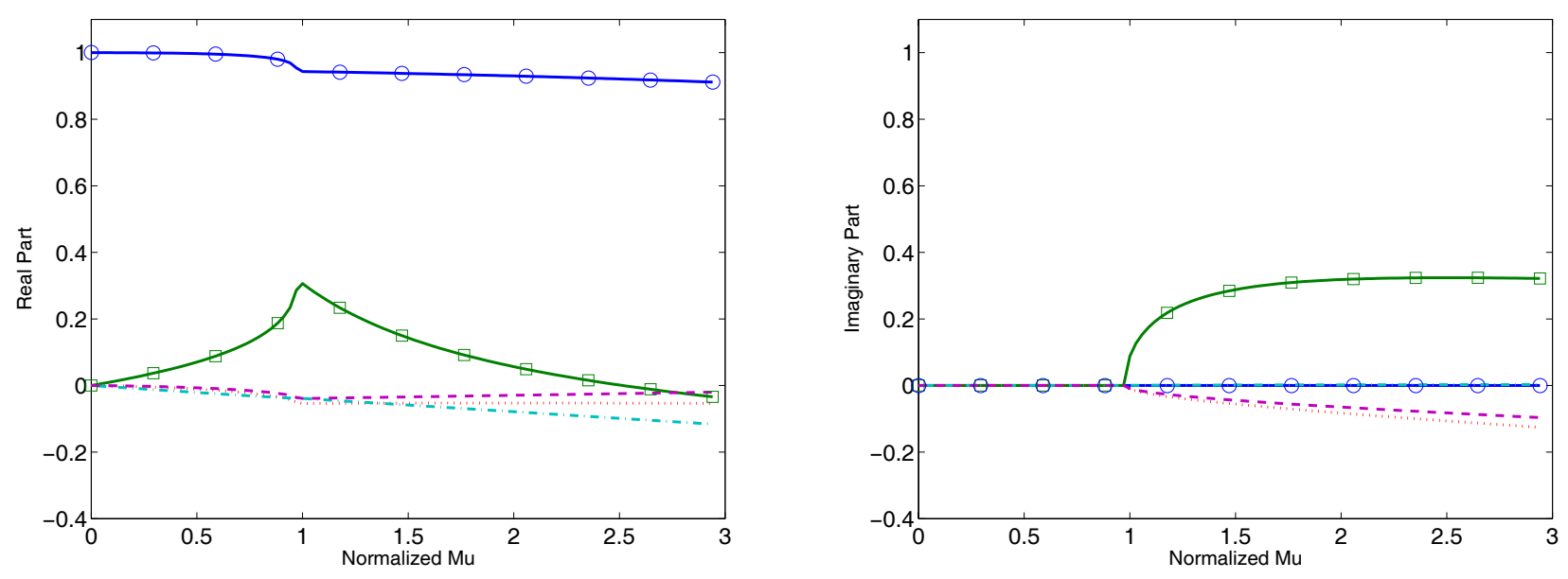

(b)

legend :

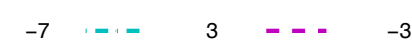

Figure 4: Undamped modal participation vectors - (a) Mode M1 - (b) Mode M2

E, defined in Table 1. As expected, the main effect of added damping is a shift of the eigenvalue real parts towards the negative values. Nevertheless, the coalescence patterns are deeply altered because of the unequal spread of damping. First, this damping distribution induces a $|d 2-d 1| / 2$ gap in real parts between the two modes at $\mu=0$. Then, the main change occurs in the vicinity of the coalescence point. As explained by Hoffmann and Gaul [18], a "smoothing effect" of the curves with respect to the friction coefficient is observed, both for real parts and frequencies. Therefore, the real parts begin splitting at a lower friction coefficient value than for the undamped situation. As a consequence, increasing the gap in damping between the two modes tends to decrease the stability range.

Though coalescence patterns are more complicated than in the undamped cases, they offer a significant advantage. Thanks to the frequency and real part shifts which are non-zero for each friction value, the unstable mode can now be clearly identified and tracked with respect to the friction coefficient value. Here, the unstable mode turns out to be the least damped mode. 

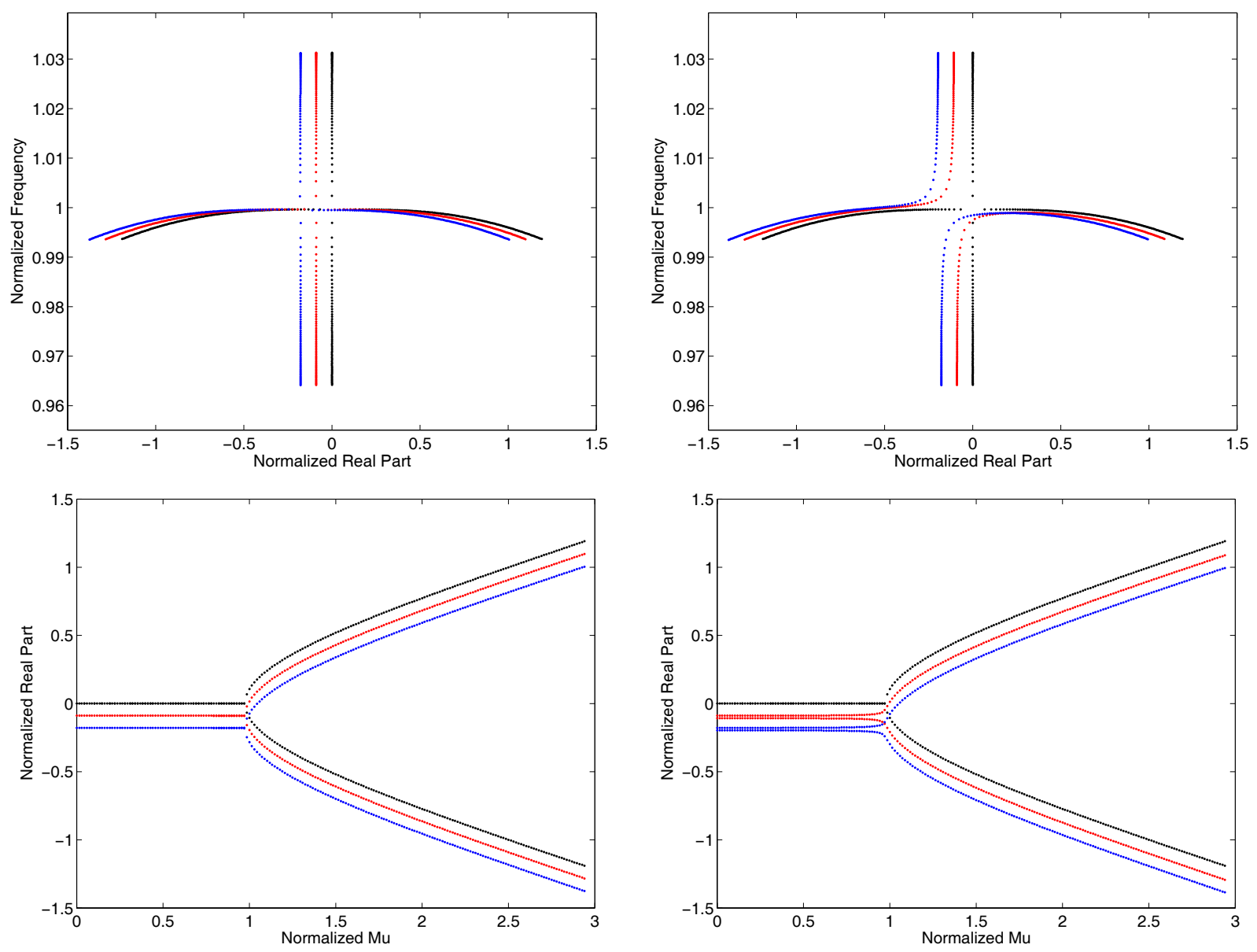

(a)

(b)

Figure 5: Damped coalescence patterns - (a) Equally damped, • Case A, • Case B, • Case C - (b) Non-equally damped, $\bullet$ Case A, • Case D, • Case E

\subsection{Unstable modes}

In Figure 5(b), basic mode tracking reveals that the unstable mode is the least damped mode. In order to confirm this point, the four possible cases corresponding to $d 1 \pm 25$ and $d 2 \pm 25$ have been computed with respect to case B. These cases are defined in Table 1 and shown in Figure 6. As expected, in each case, the unstable mode turns out to be the least damped mode.

From there, it may be interesting to investigate the effect of damping on deformed shapes. Indeed, in unequally damped cases, it is possible to track the modes, especially the unstable ones, with respect to the friction coefficient. For the sake of brevity, only cases $\mathrm{F}$ and $\mathrm{G}$ will be described in terms of modal participation factors in Figures 7 and 8, but similar conclusions might be drawn from the cases $\mathrm{H}$ and $\mathrm{I}$. We first notice that the damped modal participation factors resemble the undamped ones, except that they are smoother in the vicinity of the bifurcation point. Furthermore, $M 1$ and $M 2$ become complex before the undamped bifurcation point, defined as Normalized $\mathrm{Mu}=1.0$. The mpv real parts of $M 1$ and $M 2$ respectively, look quite the same for the cases F and G. The mpv imaginary parts are opposite between the cases $\mathrm{F}$ and $\mathrm{G}$. In other words, the deformed shape of the unstable mode has a positive imaginary 


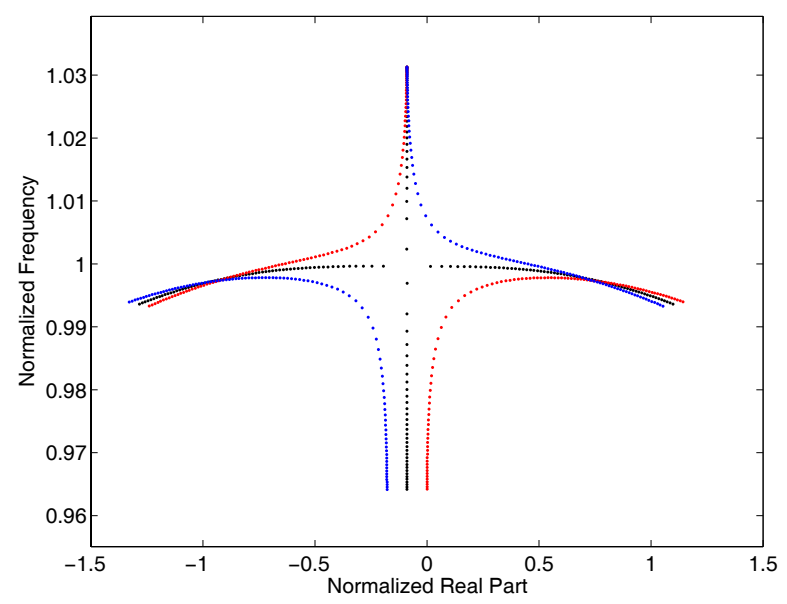

(a)

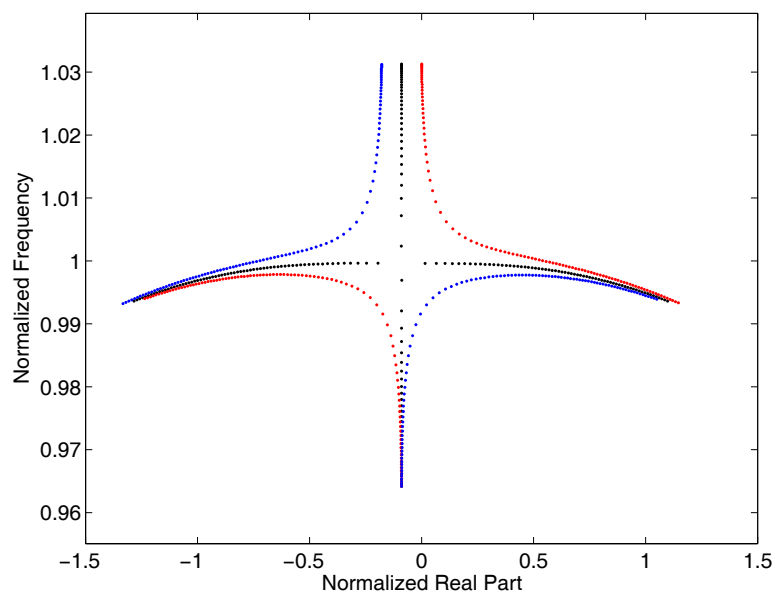

(b)

Figure 6: Tracking of the unstable mode on the damped coalescence patterns - (a) $\bullet$ Case B, $\bullet$ Case F, $\bullet$ Case G - (b) • Case B, • Case H, • Case I

part, whereas the deformed shape of the stable mode has a negative one.

\subsection{Stability areas}

As described in the previous section, the addition of modal damping has complicated effects on coupling patterns. Nevertheless the main point is to assess its effect on brake stability.

It can be inferred from Figure 6 that the ratio between the two dampings $d 1$ and $d 2$ must be a key parameter influencing the stability of the corresponding two modes. Figure 9 gives stability charts resulting from a bi-parametric stability analysis involving $\mu$ and $\frac{d 2}{d 1}$. The three stability charts, whose ordinate axes are logarithmically spaced, refer respectively to the following values of $d 1:\{1,10,20\}$. For each couple of the two parameters, a white area means that the system is stable whereas a gray area means that one mode has a positive eigenvalue real part. The three charts feature the same range of $\frac{d 2}{d 1}$, but their limit of validity are not the same. Indeed, for our system, $d$ has physical meaning only up to around 100. For $d 1=1$, the most stable configuration is the equally damped case, corresponding to $\frac{d 2}{d 1}=1$. A shift in damping from this point makes the range of stability decrease. For higher values of $d_{1}$, the most stable case is also the equally damped case. Nevertheless, the frontier between the stable and unstable cases features a local minimum of the stability range. This minimum tends to shift towards the lower values of $\frac{d 2}{d 1}=1$ as $d_{1}$ increases. Moreover, Figures 9(b), (d) and (f) show the merging scenario and the stability behaviour of the two coupling modes. It clearly appears that the stable mode (corresponding to the blue surface) is the mode that features the highest frequency of the two coupling modes if $\frac{d 2}{d 1}<1$. Then, for $\frac{d_{2}}{d_{1}}>1$, the stable mode is the mode that features the lowest frequency of the two coupling modes. It may be concluded that a more stable system is obtained for $\frac{d 2}{d 1}=1$ when stable and unstable frequencies reverse. To go further, a full factorial design of experiments has been launched with respect to $d 1$ and $d 2$. The results are given in Figure 10 for several values of the friction coefficient. The first chart, corresponding to $\mu=0.59$, shows that the stable area is a stripe centred on the equally damped case. Moreover, it highlights the phenomenon of destabilisation induced by damping. Indeed, assuming 

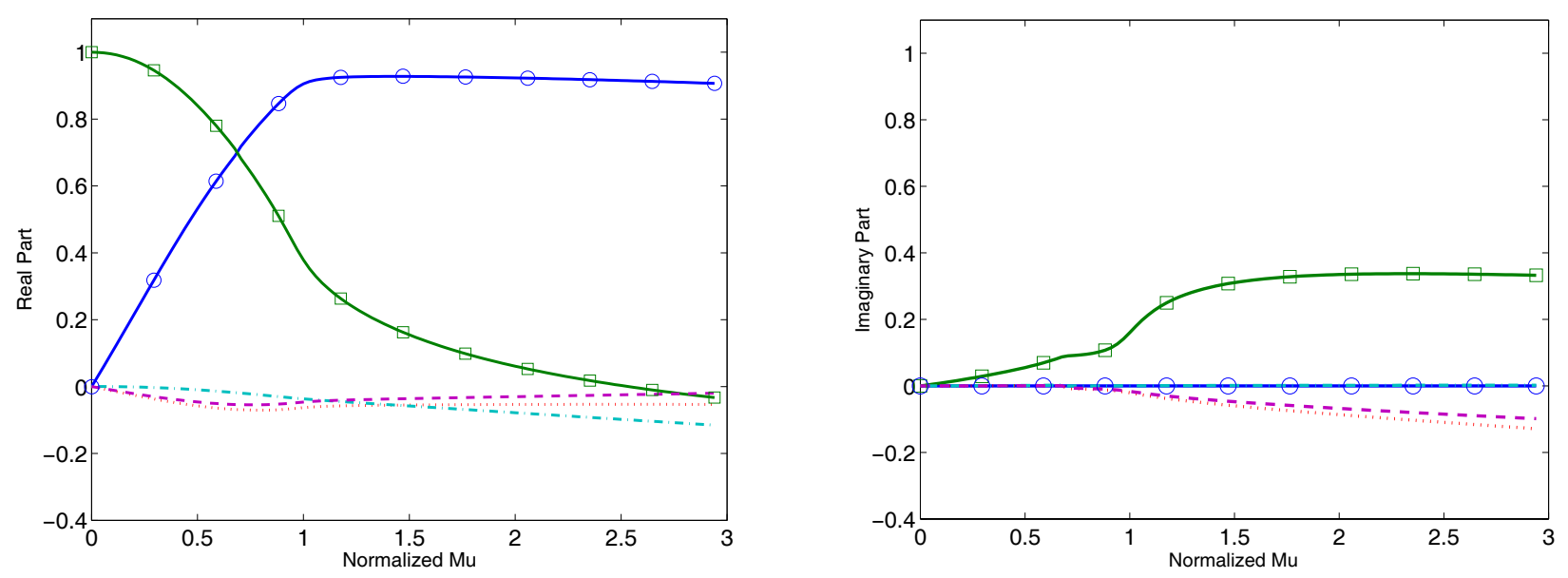

(a)

legend :
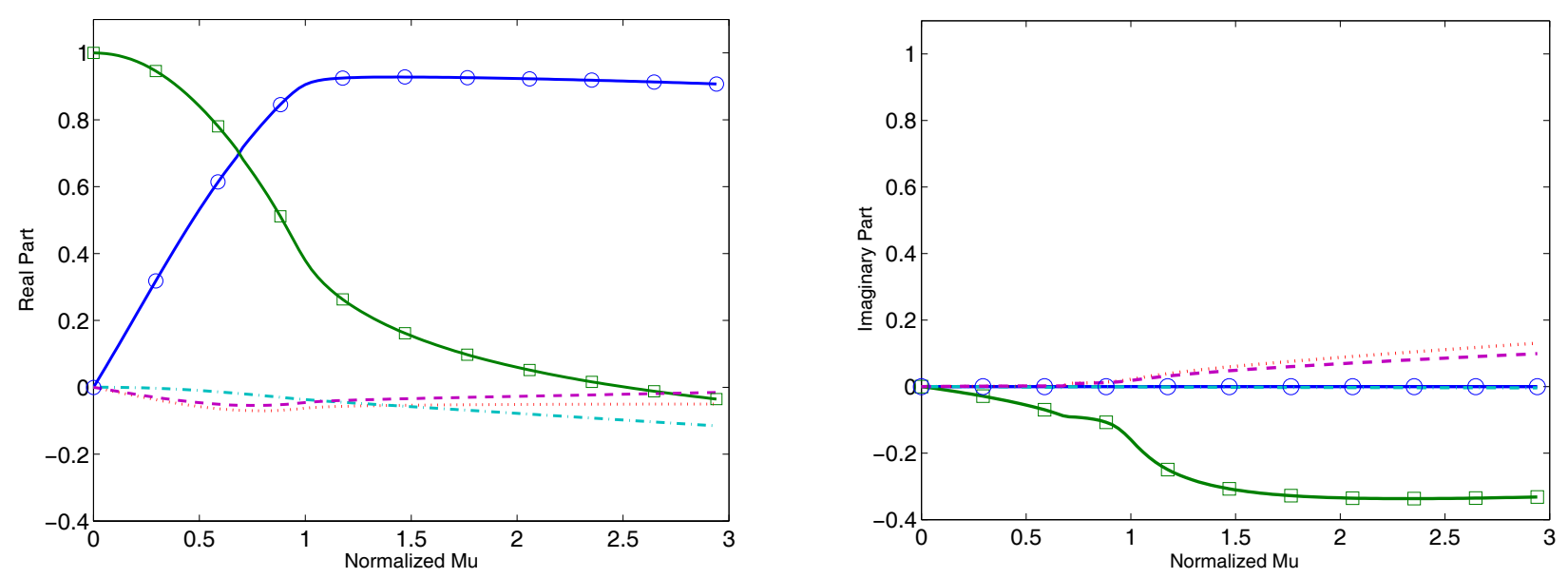

(b)

legend :

Figure 7: Damped modal participation factors of M1 - (a) Case F - (b) Case G

that either $d 1$ or $d 2$ is fixed at a low value, increasing the other one tends to cross the frontier of stability and makes the system unstable. As the friction coefficient increases, the stable stripe shrinks. Beyond the undamped bifurcation point, the system is unstable, unless the two modes are sufficiently damped, in an equal way. This phenomenon is highlighted in the $\mu=1.00$ curve since the stability area is located in the right upper corner of the chart. Then, Figure 11 indicates the evolution of stable and unstable modes. As previously explained, the stable and unstable modes (and the value of the corresponding frequencies) reverse when the structural damping ratio $\frac{d 2}{d 1}$ is equal to 1 .

\subsection{Application of the Robust Damping Factor (RD-Factor)}

In this section, the criterion called Robust Damping Factor (RD-factor) defined by Sinou et al. [31] is investigated in order to obtain the optimal damping ratio $\frac{d 2}{d 1}$ for a given set of physical parameters. 

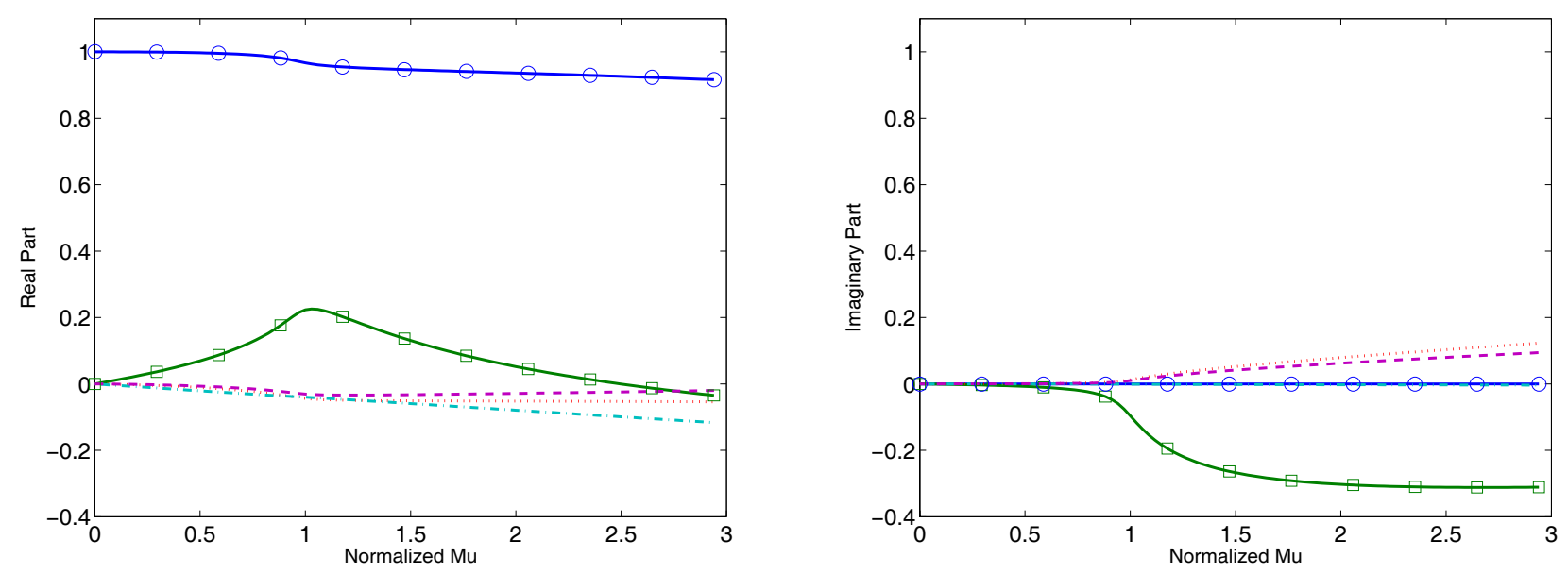

(a)

legend :
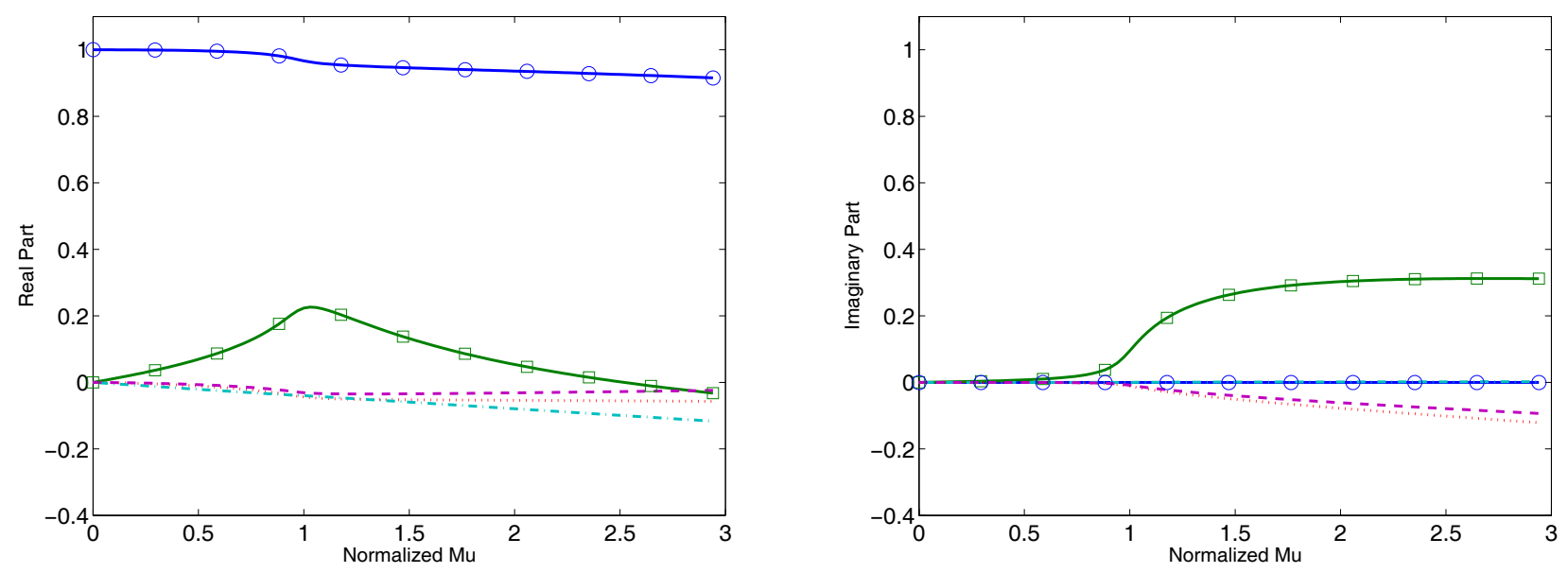

(b)

legend :

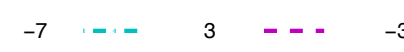

Figure 8: Damped modal participation factors of M2 - (a) Case F - (b) Case G

The Robust Damping Factor is defined as a function of the real parts of eigenvalues (that define the stability of the mechanical system) and the relative values between the two frequencies of the merging modes. The Robust Damping Factor criterion may be given by [31]

$$
\begin{array}{ll}
R D-\text { Factor }=-\operatorname{Max}(\operatorname{Re}(\lambda)) \log \left(\frac{\Delta F}{\Delta R+1}+1\right) & \text { if } \operatorname{Re}(\lambda) \leq 0 \\
R D-\text { Factor }=0 & \text { if } \operatorname{Re}(\lambda)>0
\end{array}
$$

where $-\operatorname{Max}(\operatorname{Re}(\lambda))$ may be defined as the distance between the greatest real part and the zero real part axis. $\Delta R$ and $\Delta F$ define the difference between the real parts and the associated imaginary parts of the two coupling modes. They are given by

$$
\begin{aligned}
& \Delta R=\left|\operatorname{Re}\left(\lambda_{\text {unstable }}\right)-\operatorname{Re}\left(\lambda_{\text {stable }}\right)\right| \\
& \Delta F=\left|\operatorname{Im}\left(\lambda_{\text {unstable }}\right)-\operatorname{Im}\left(\lambda_{\text {stable }}\right)\right|
\end{aligned}
$$




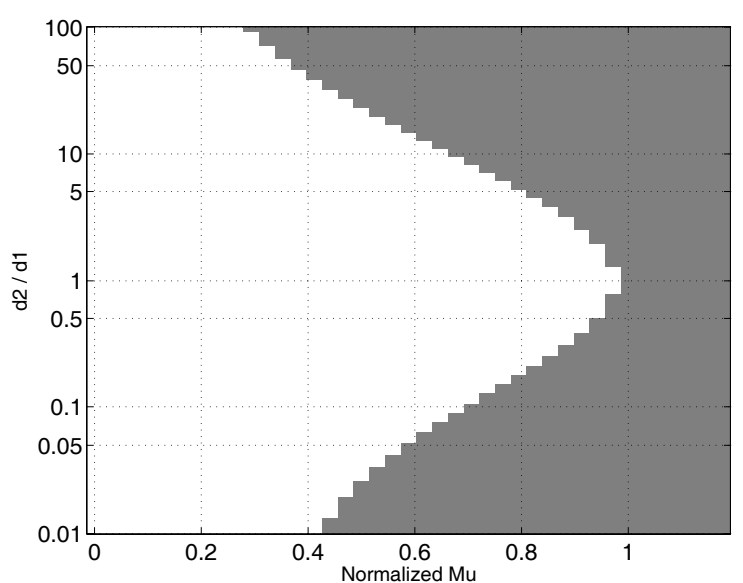

(a)

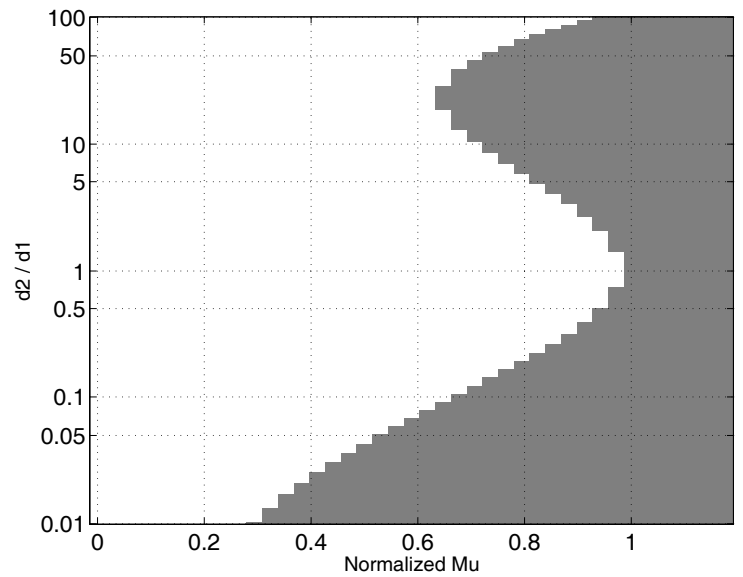

(c)

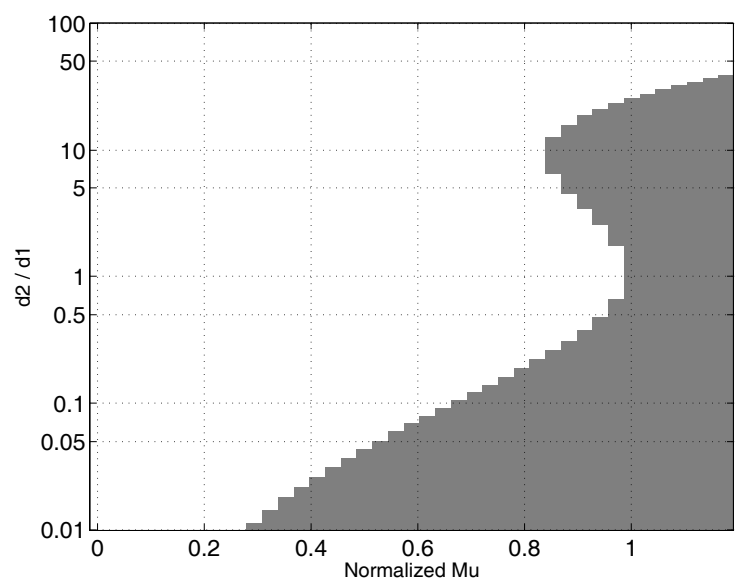

(e)

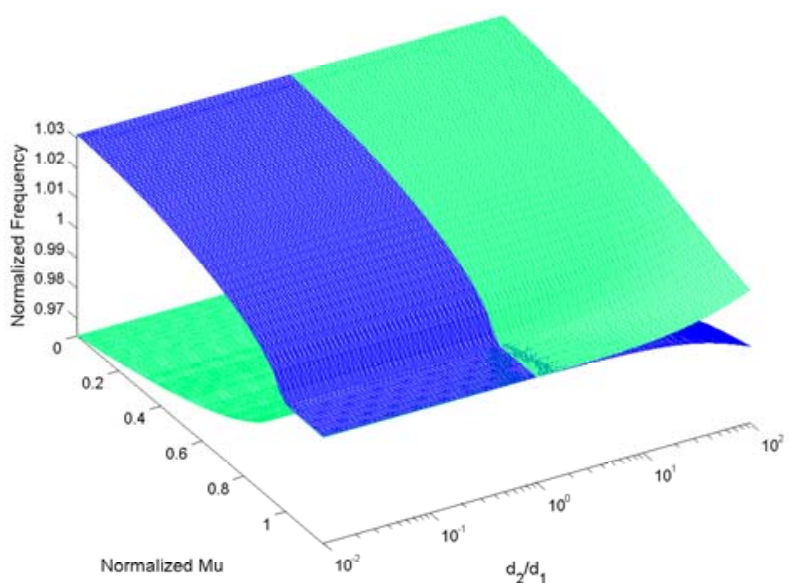

(b)

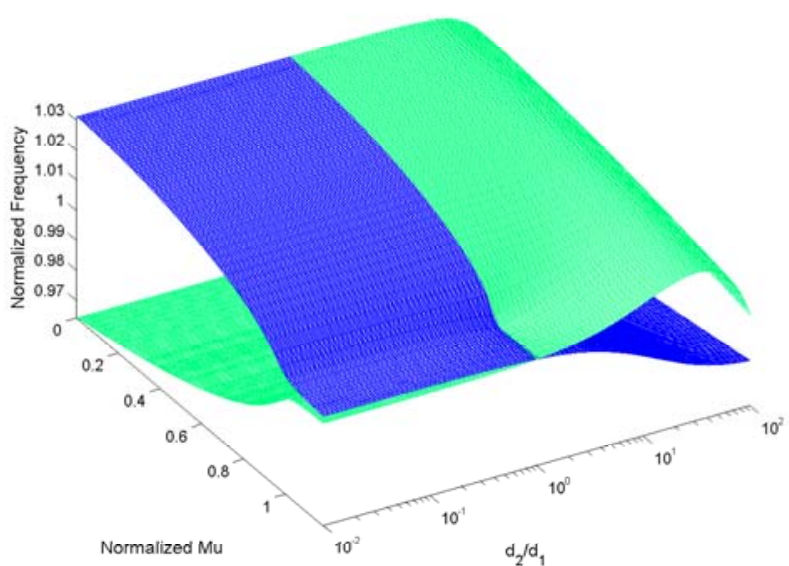

(d)

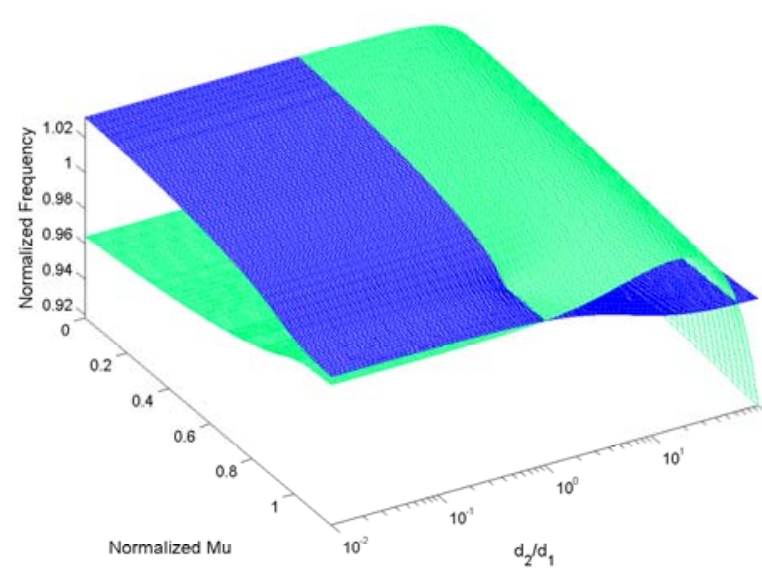

(f)

Figure 9: Stability areas $(\mu, d 2 / d 1)$ and evolution of the stable and unstable modes (green surface $=$ unstable mode, blue surface=stable mode $)$ - $(a, c, e)$ : Stability areas respectively for $d 1=1, d 1=10$ and $d 1=20-(b, d, f)$ : Evolution of the stable and unstable modes respectively for $d 1=1, d 1=10$ and $d 1=20$ 


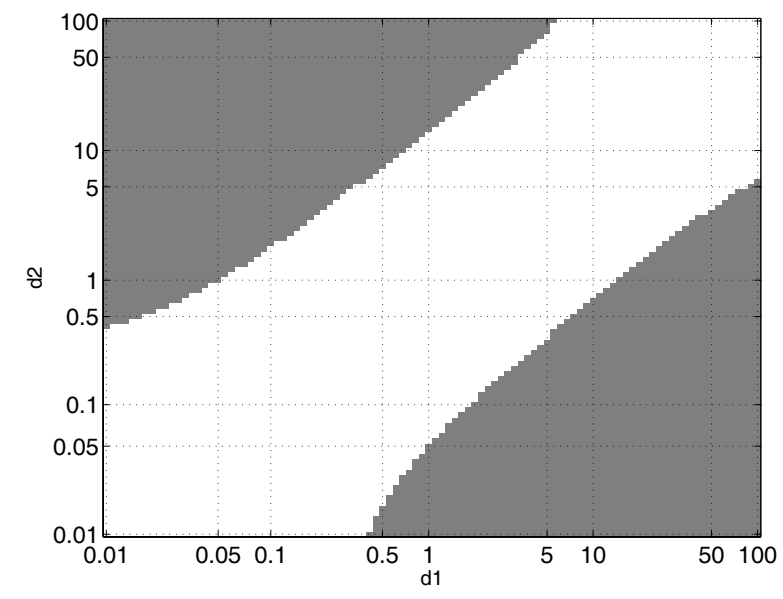

(a)

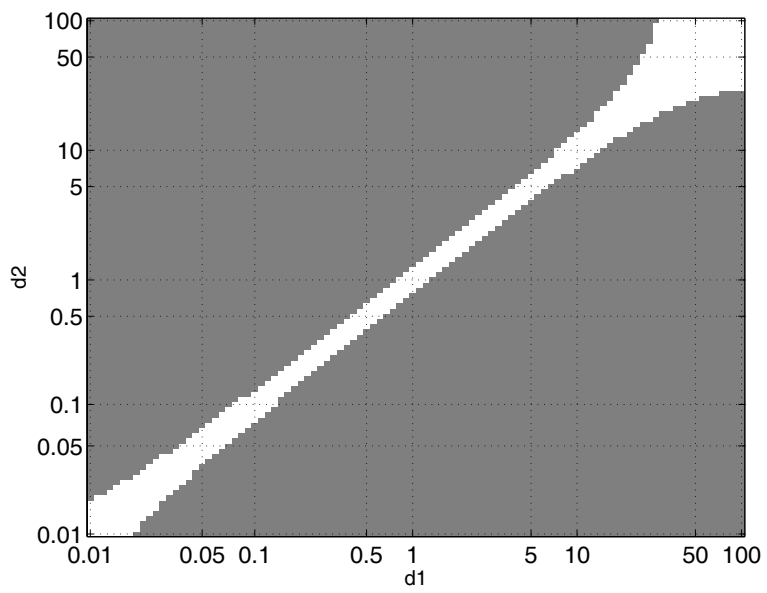

(c)

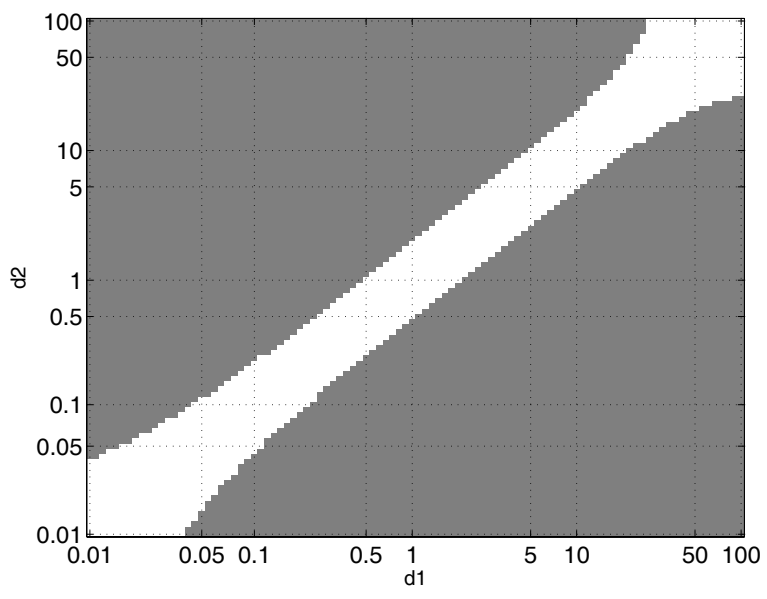

(b)

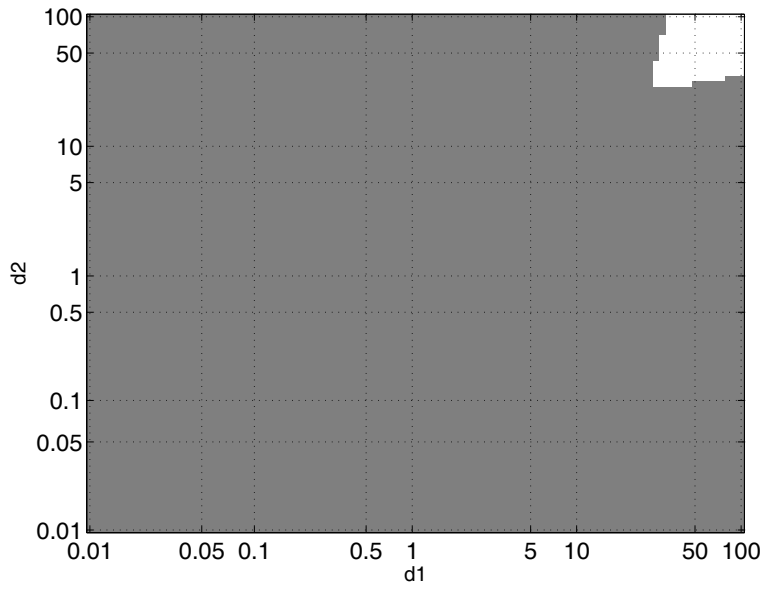

(d)

Figure 10: Stability areas $(d 1, d 2)$. (a): normalized $\mu=0.59$ - (b): normalized $\mu=0.94$ - (c): normalized $\mu=0.97-(\mathrm{d})$ : normalized $\mu=1.00$

\begin{tabular}{|l||c|c|c|c|}
\hline Situation & Case & $d 1$ & $d 2$ & $\mu_{c}$ \\
\hline \hline Undamped & $\mathrm{A}$ & 0 & 0 & 1.00 \\
\hline Equally damped & $\mathrm{B}$ & 25 & 25 & 1.07 \\
\cline { 2 - 5 } & $\mathrm{C}$ & 50 & 50 & 1.27 \\
\hline Non-equally damped & $\mathrm{D}$ & 25 & 30 & 1.07 \\
\cline { 2 - 5 } & $\mathrm{E}$ & 50 & 55 & 1.32 \\
\hline \hline Additional cases & $\mathrm{F}$ & 0 & 25 & 0.33 \\
& $\mathrm{G}$ & 50 & 25 & 0.98 \\
& $\mathrm{H}$ & 25 & 0 & 0.33 \\
& $\mathrm{I}$ & 25 & 50 & 0.98 \\
\hline
\end{tabular}

Table 1: Critical values of the friction coefficient 


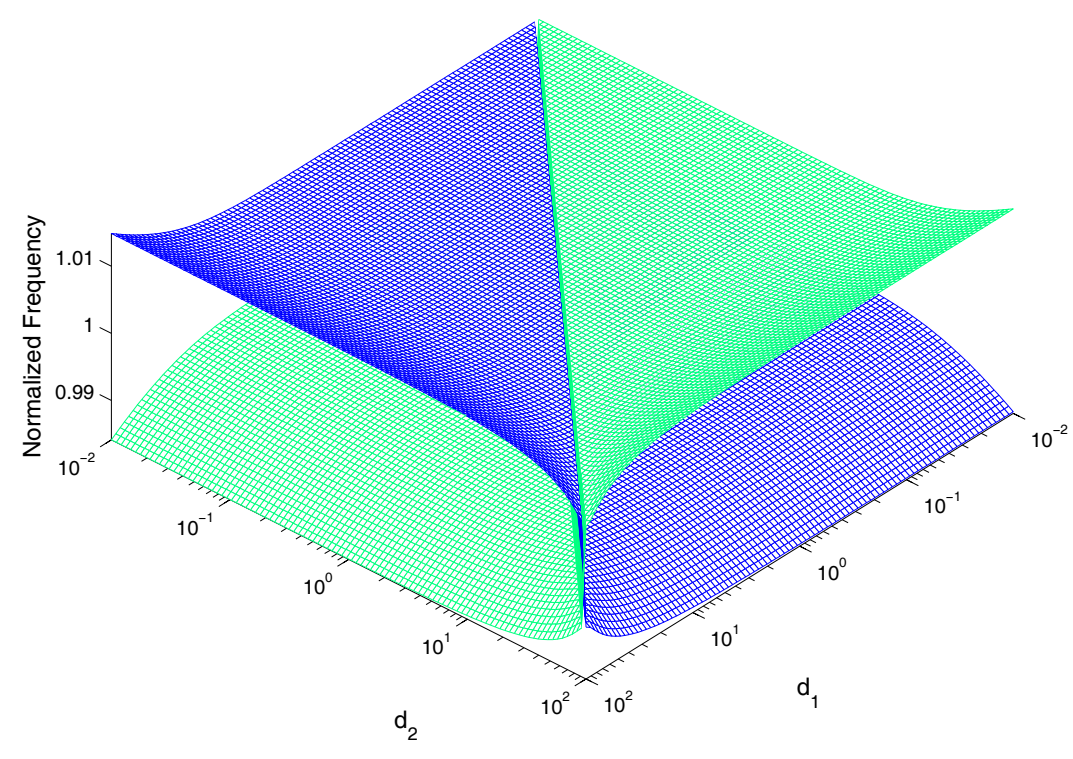

Figure 11: Evolution of the stable and unstable modes $(d 1, d 2)$ for the normalized $\mu=0.97$ (green surface $=$ unstable mode, blue surface $=$ stable mode)

where $\operatorname{Im}(\lambda)$ and $\operatorname{Re}(\lambda)$ define the imaginary and real parts of $\lambda$. Here, we have assumed that flutter instability is composed of two modes among which only one is unstable. The most robust damping ratio of $\frac{d 2}{d 1}$ corresponds to the highest value of the Robust Damping Factor (for various values of $d 1$ or $d_{2}$ while keeping the other physical parameters) : it is given by the smallest difference between the real parts of the two merging modes (this difference is equal to zero when the stable and unstable modes reverse) and the greatest difference between the two frequencies (for which the associated real parts are equal to zero).

Figures 12(a) and (b) illustrate the evolution of the Robust Damping Factor (RD-Factor) versus the damping ratio $\frac{d 2}{d 1}$ and the normalized friction coefficient for two values of $d_{1}$. The variability of the RDFactor versus $d 2$ and $d 1$ for two values of the normalized friction coefficient is shown in Figures 12(c) and (d). Considering Figures 12(c) and (d), the greater the proportional structural damping (for $d 1=d 2$ ), the greater the Robust Dampnig Factor. So the RD-Factor shows that by increasing equal structural damping $d 1=d 2$, the system is more stable due to the fact that the real parts of the eigenvalues are translated towards the negative real parts. Considering Figures 12(a) and (b), the Robust Damping Factor is greater when the damping ratio $\frac{d 2}{d 1}$ is equal to 1 , even if the damping value $d 1$ varies. In both cases, the same area is obtained for the most robust damping ratio. We see that this area corresponds to the zone of the merging scenario of the two coupling modes (as indicated in Figures 9(b), (d), (e) and Figure11). So, the Robust Damping helps avoid design errors and reduce flutter instability. As previously explained, introducing proportional structural damping between the stable and unstable modes $(d 1=d 2)$ may be used in order to enhance the stability of mechanical systems. 


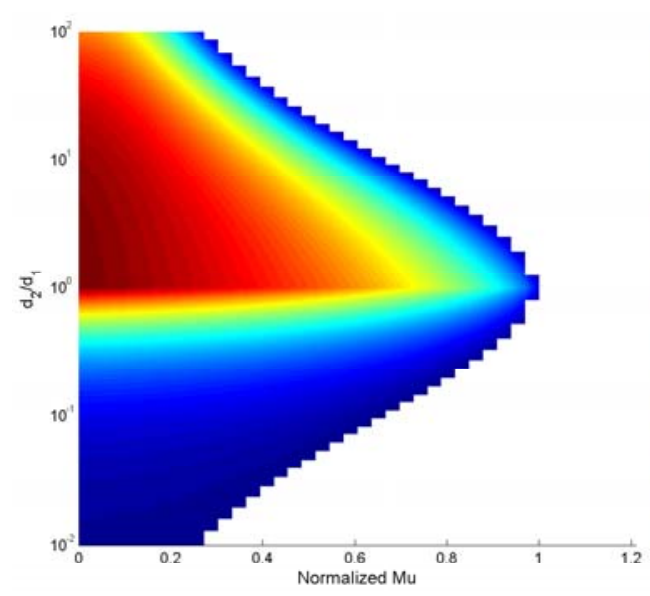

(a)

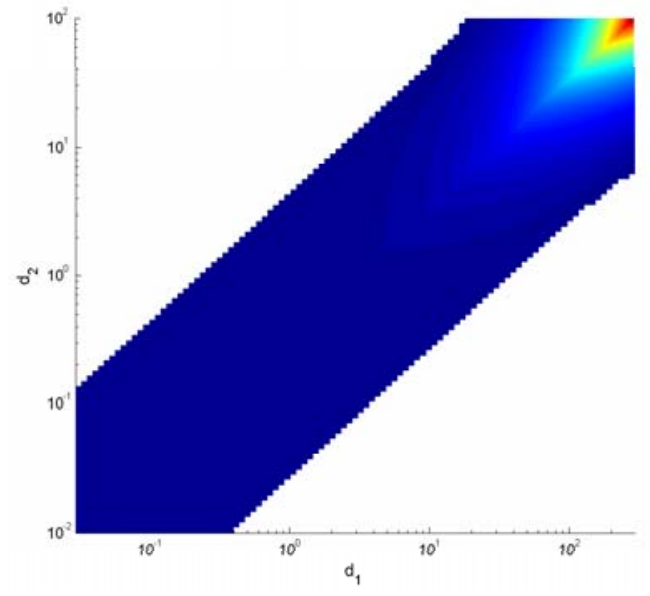

(c)
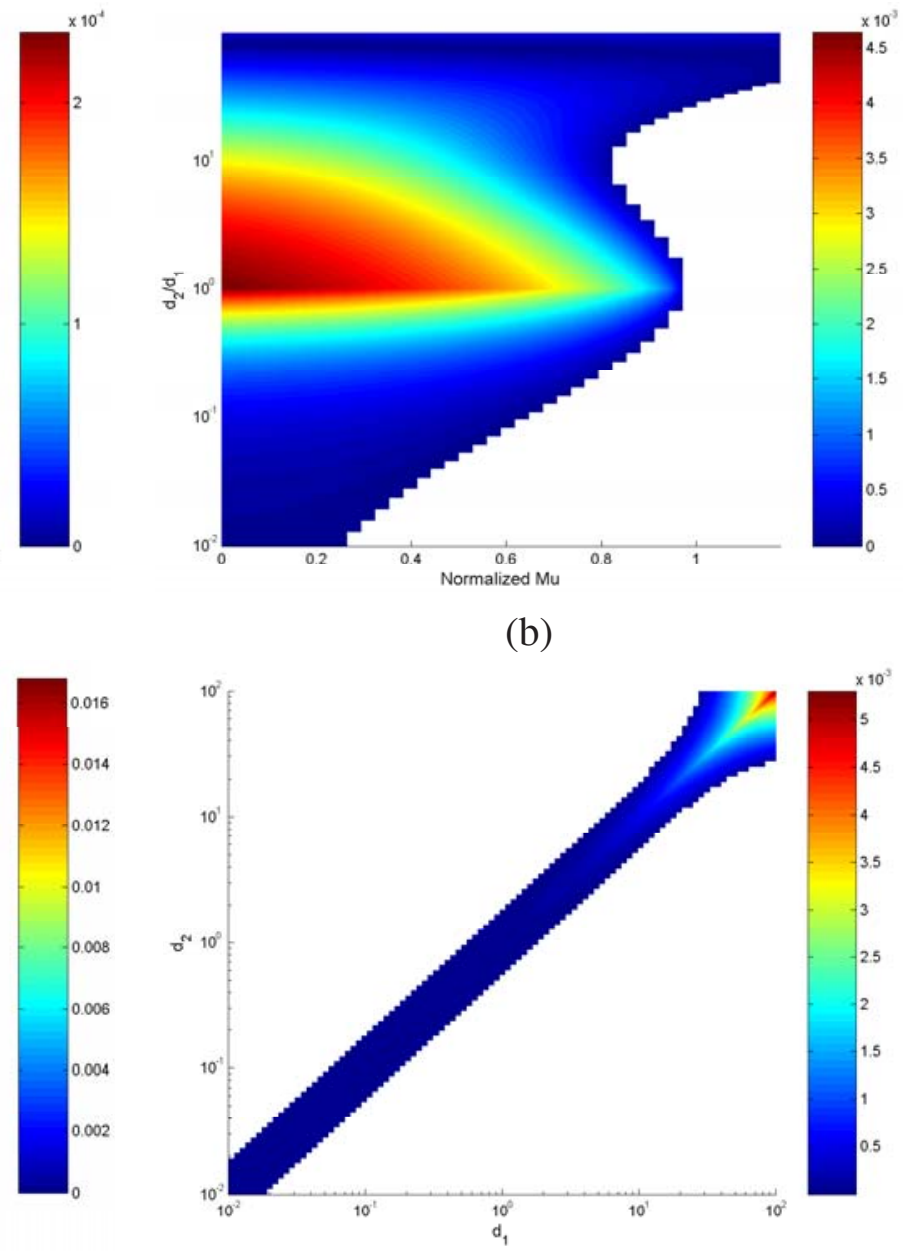

(d)

Figure 12: Evolution of the Robust Damping Factor - (a): $d 1=1$ - (b): $d 1=20$ - (c): normalized $\mu=0.59$ - (d): normalized $\mu=0.97$ 


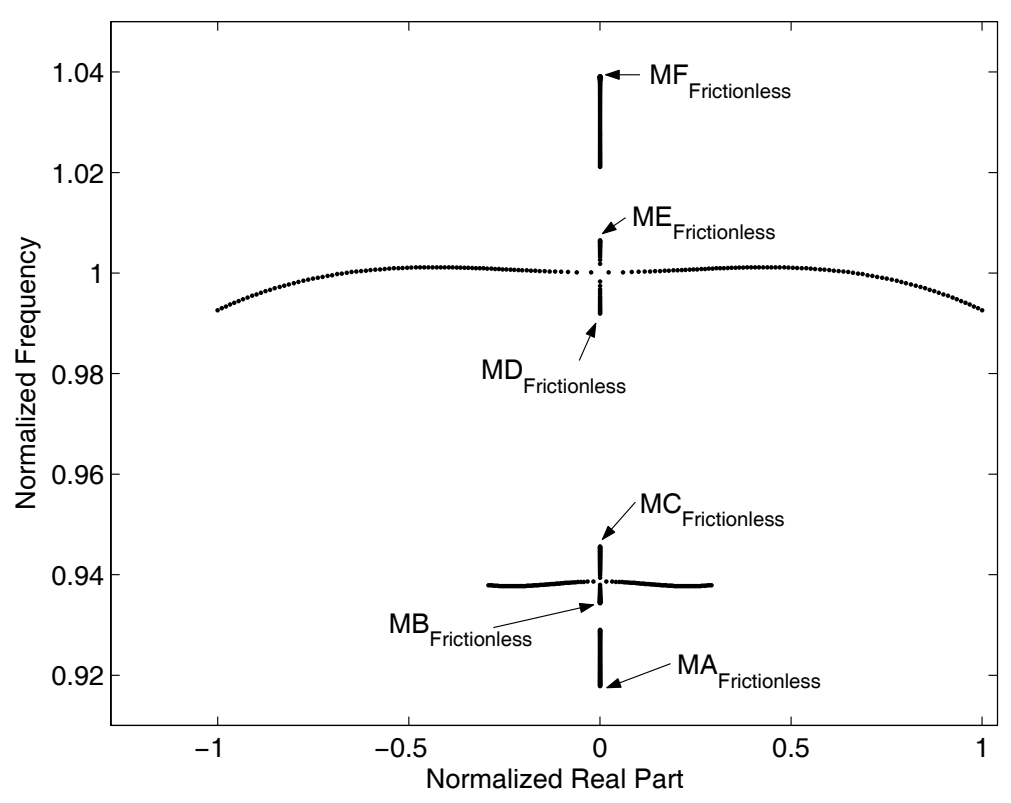

Figure 13: Evolution of the undamped eigenvalues in the complex plane - modes MA to MF

\section{Patterns involving more than two modes}

\subsection{Undamped coupling patterns}

The previously described coupling patterns involved only two modes. This kind of behaviour is more likely to be found in very low frequency squeals. For higher frequency squeals, the phenomena are more complicated, since the modal density is higher. In order to illustrate this point, Figure 13 shows the evolution, in the complex plane, of six consecutive modes as a function of the friction coefficient. These modes are referred to as $M A$ to $M F$ with increasing frequencies.

Their frictionless deformed shapes, shown in Figure 14, are analysed below.

$M A$ : this mode features a twisting of the knuckle. The lower and upper outer parts of the anchor bracket twist in-phase along the guiding pin axis. As a consequence, the beam deflects. The disc undergoes vibrations of low magnitude corresponding to a 3 nodal diameter bending mode. The inner pad slips on the disc surface, along the orthoradial direction, between its abutments.

$M B$ : the knuckle mounts, which vibrate in anti-phase, drive the anchor bracket in a twisting mode which resembles the one involved in $M A$. Driven by the calliper, the piston slips on the inner back plate in the radial direction. The inner lining deflects in compression and the disc deflects in a so-called umbrella mode.

$M C$ : this mode consists mainly of a calliper bending and an umbrella mode of the disc. The inner pad slips on the disc surface, along the orthoradial direction, between its abutments. The inner lining deflects in compression. The anchor bracket behaves in the same way as it does in mode $M A$ 


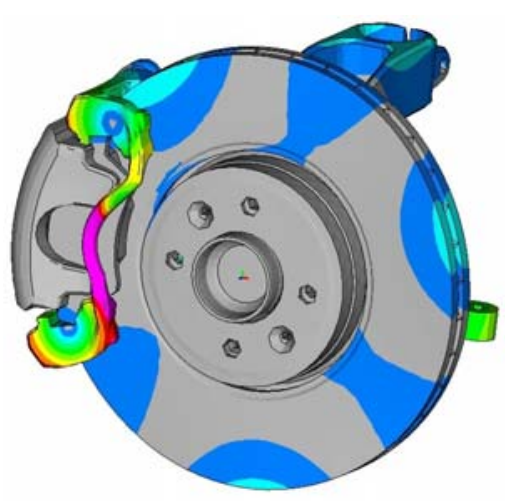

$M A_{\text {Frictionless }}$

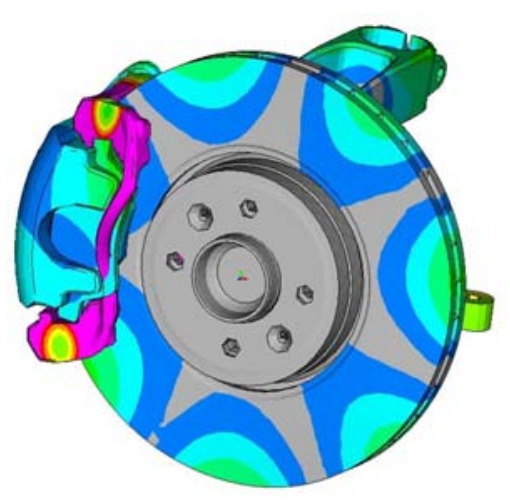

$M D_{\text {Frictionless }}$

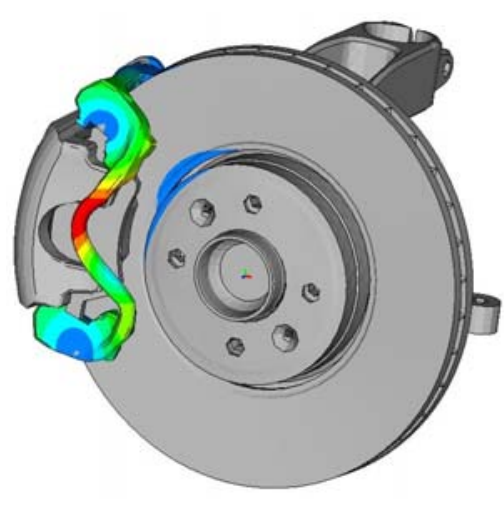

$M B_{\text {Frictionless }}$

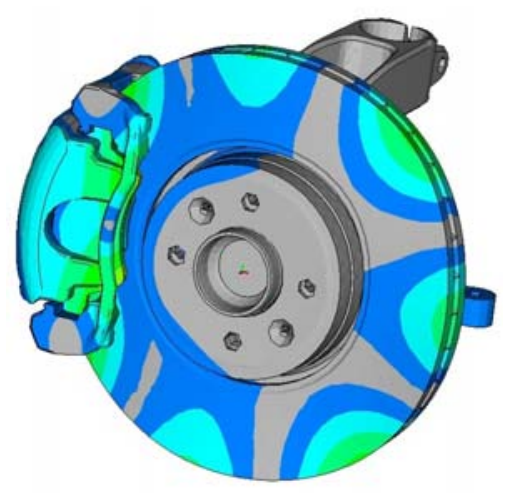

$M E_{\text {Frictionless }}$

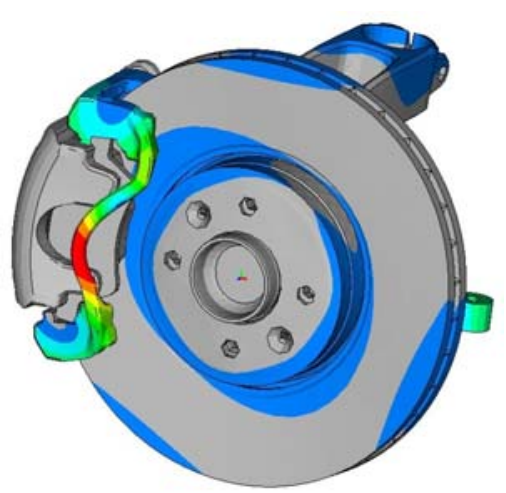

$M C_{\text {Frictionless }}$

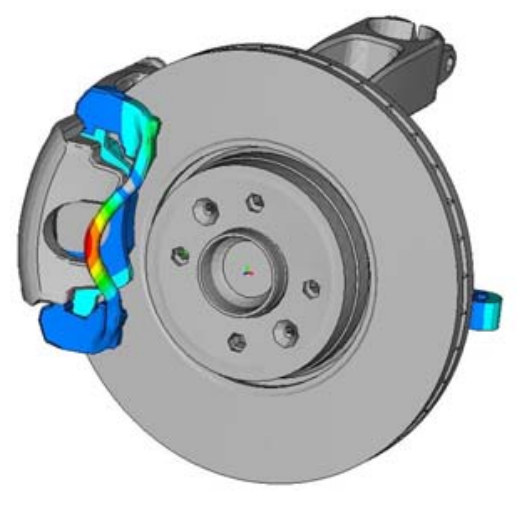

$M F_{\text {Frictionless }}$

Figure 14: Deformed shapes of modes MA to MF in the frictionless situation

$M D:$ the knuckle mounts vibrate in anti-phase. The anchor bracket undergoes a large magnitude "opening mode", which is in anti-phase between up and down. Here, an "opening mode" means that the two parts of the anchor bracket, on both sides of the disc, tend to separate from each other. The calliper bends, the inner pad slips between its abutments and the linings deflect in compression. The disc features a 3 nodal diameter bending mode, with a nodal line under the middle of the pads.

$M E$ : The anchor bracket undergoes a low magnitude opening mode. The calliper bends with large magnitude displacements. The inner pad bends and the outer lining deflects in compression. The disc features a 3 nodal diameter bending mode, with an anti-nodal line under the middle of the pads.

$M F$ : the knuckle mounts vibrate in-phase. The anchor bracket beam undergoes large magnitude displacements. The calliper bends and the disc deflects in an umbrella mode. The inner pad slips between its abutments. The outer pad undergoes a rigid body rotation, keeping contact with the disc.

Some of these frictionless modes appear to be quite similar. Especially, the two pairs of modes $M B-$ $M C$ and $M D-M E$ feature the same disc vibration pattern, respectively an umbrella mode and a 3 
nodal line bending mode. Moreover, $M D$ and $M E$ deal with disc doublet modes [1,32]. The two pairs of modes, $M B-M C$ and $M D-M E$, may be named "compatible" modes, as used by Huang et al. in [30]. Looking back on Figure 13, this point is confirmed since $M B-M C$ and $M D-M E$ are coupled as the friction coefficient increases. Their critical friction coefficients are respectiely $\mu c_{B C}=2.37$ and $\mu c_{D E}=1.00$. Note that the data have been normalized with respect to the most critical bifurcation point, the one that involves $M D$ and $M E$.

As far as the deformed shapes are concerned, the evolution of modal factors are shown in Figures 15 and 16 respectively for the $M B-M C$ and $M D-M E$ couplings. The first point to notice in Figure 15 is that three modes are mainly involved in the $M B-M C$ coupling: obviously $M B_{\text {Frictionless }}$ and $M C_{\text {Frictionless }}$ but also $M A_{\text {Frictionless. }}$ As friction increases, the participation of $M B_{\text {Frictionless }}$ on the real part of $M B$ decreases and the participation of $M A_{\text {Frictionless }}$ and $M C_{\text {Frictionless }}$ grows. As far as $M C$ is concerned, the same kind of behaviour can be observed, with the roles played by $M B_{\text {Frictionless }}$ and $M C_{\text {Frictionless }}$ reversed. After the bifurcation point that occurs at $\mu c_{B C}=2.37$, the contribution of $M A_{\text {Frictionless }}$ has a very strong impact on the real parts. Meanwhile, the contributions of $M B_{\text {Frictionless }}$ and $M C_{\text {Frictionless }}$ decrease on the real parts and increase on the imaginary parts. Finally, $M A_{\text {Frictionless }}$ drives the real parts whereas $M B_{\text {Frictionless }}$ and $M C_{\text {Frictionless }}$ drive the imaginary parts of $M B$ and $M C$.

For the $M D-M E$ coupling, the phenomena at stake are even more complicated. Figure 16 illustrates that six frictionless modes have significant contributions on the deformed shapes of $M D$ and $M E$. These frictionless modes are $M A, M C, M D, M E, M F$ and $M G$, which is beyond the scope of Figure 13. After the bifurcation point, which occurs at $\mu c_{D E}=1.00, M D_{\text {Frictionless }}$ drives the real parts and $M F_{\text {Frictionless }}$ and $M G_{\text {Frictionless }}$ drive the imaginary parts of $M D$ and $M E$.

\subsection{Damped coupling patterns}

This section focuses on the effect of modal damping on the coupling patterns shown in Figure 13. In previous sections, the damping effect was restricted to the coupling which involves the damped mode. Here, the phenomena are more complicated. The first point to notice is that the terms provided by $\boldsymbol{\Lambda}_{\mathbf{f}}$ in Equation 6 couple the modes with each other. It can be inferred from Figure 17, which gathers these terms for modes $M A$ to $M G$, that the equations governing these seven modes are strongly coupled.

As a consequence, introducing modal damping on a particular mode will not only modify its coupling pattern, but also alter the behaviour of the other modes. This point is illustrated in Figure 18, in which only $M D$ has been damped. As expected, the $M D-M E$ coupling pattern is altered in the same way as described in the previous sections. Nevertheless, the $M B-M C$ coupling pattern is also disturbed. $M B$ is stable whereas $M C$ is unstable. Moreover, $M A$ and $M F$, which are not involved in any coalescence, are stabilized.

The effect of damping is far from being fully understood. Indeed, Figure 19 illustrates a specific case of damping effect in which only the highest frequency mode has been progressively damped, from $d=0$ to $d=1500$. These curves highlight 3 eigenvalue veerings, respectively for the following transitions: $(d=600 \rightarrow d=700),(d=800 \rightarrow d=1000),(d=1300 \rightarrow d=1400)$. 

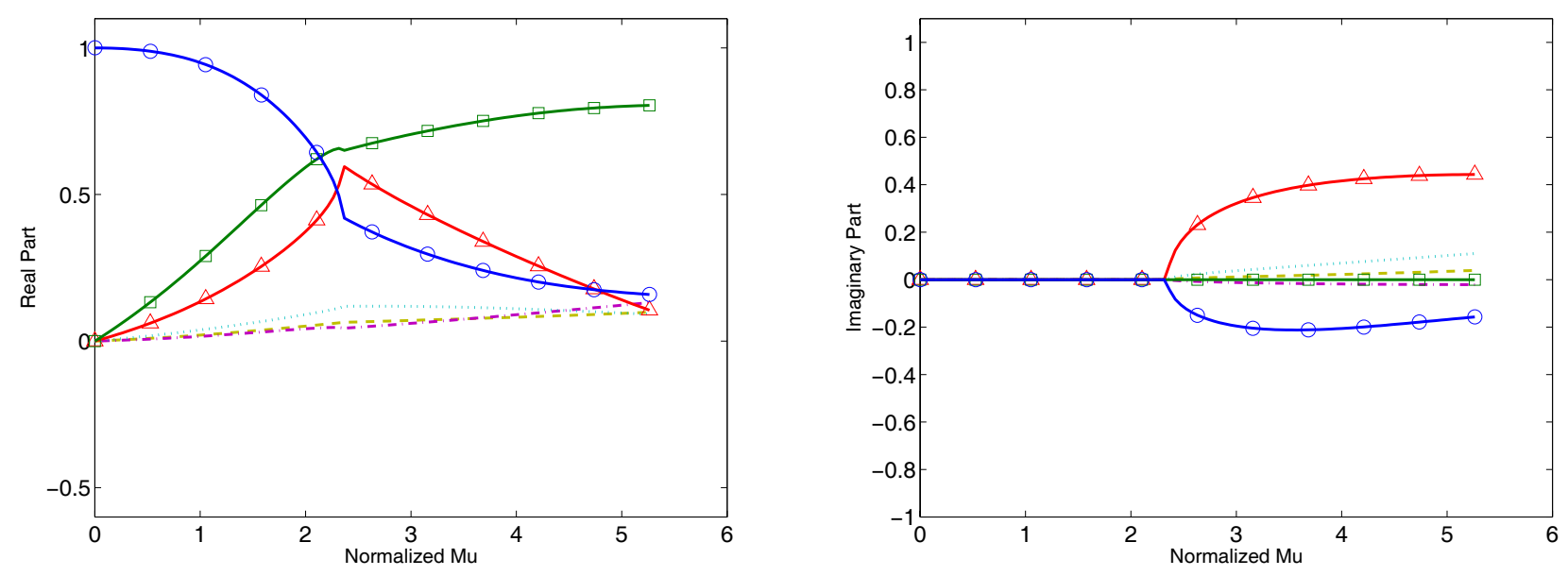

(a)

legend :
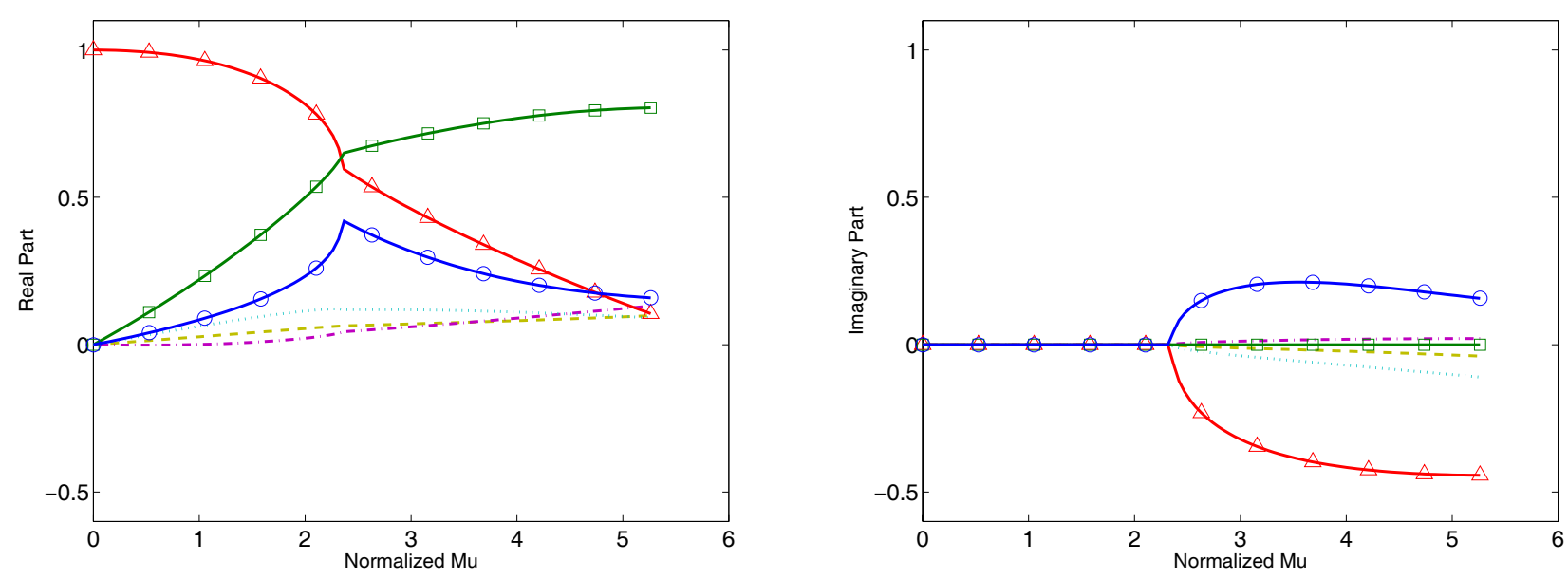

(b)

legend :

Figure 15: Undamped modal participation factors - (a): $M B$ - (b): $M C$

\section{Conclusion}

In this study, brake squeal has been analysed as a mode coupling phenomenon induced by friction. The effects of damping on the way the two modes tends to couple has been investigated. First, the modal behaviour of the system has been assessed with the finite element method. The system eigenvalues have been computed with respect to the friction coefficient. Coalescence patterns which depict the evolution of eigenvalues with respect to the friction coefficient have been determined. Then, damping has been taken into account by means of modal damping. If the two modes involved in the coalescence are equally damped, damping stabilizes the system by shifting the eigenvalues towards the negative real parts. This effect is referred to as the "lowering effect". If the two modes are not equally damped, damping proves to have two different effects: a "lowering effect" and a "smoothing effect". The lowering effect tends to stabilize the system, as in the equally damped case. Nevertheless, if the smoothing effect prevails, added 

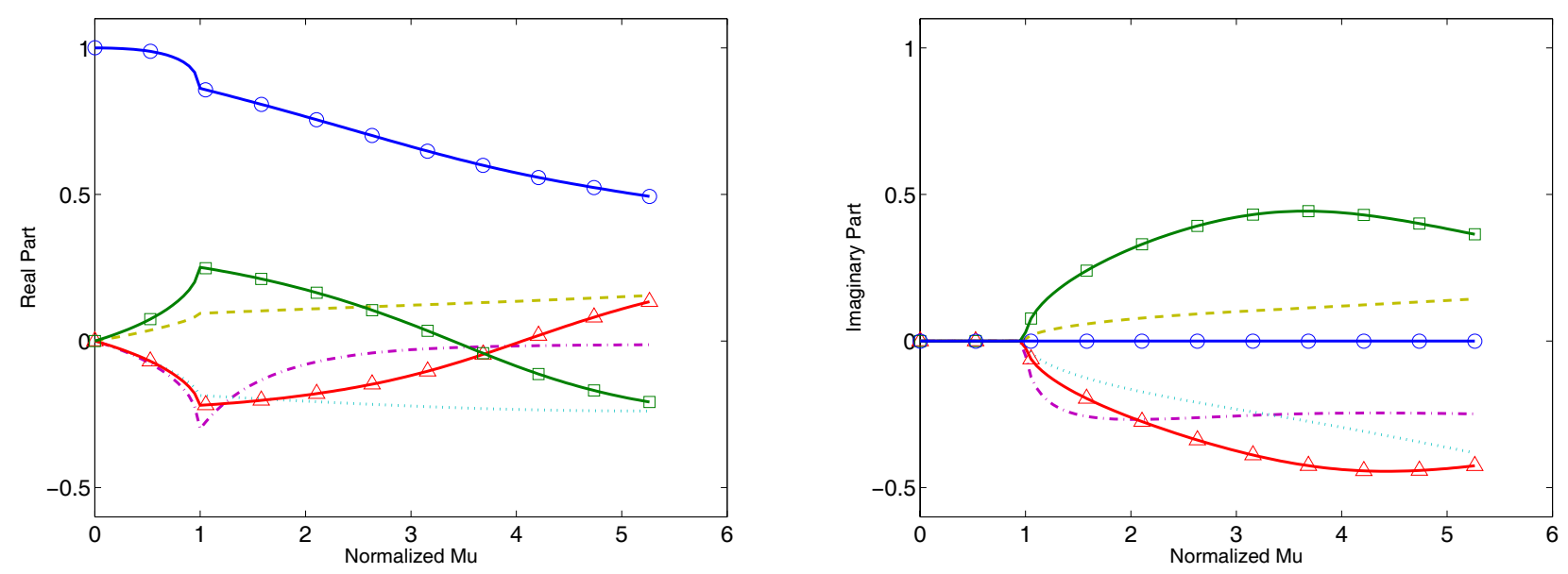

(a)

legend :
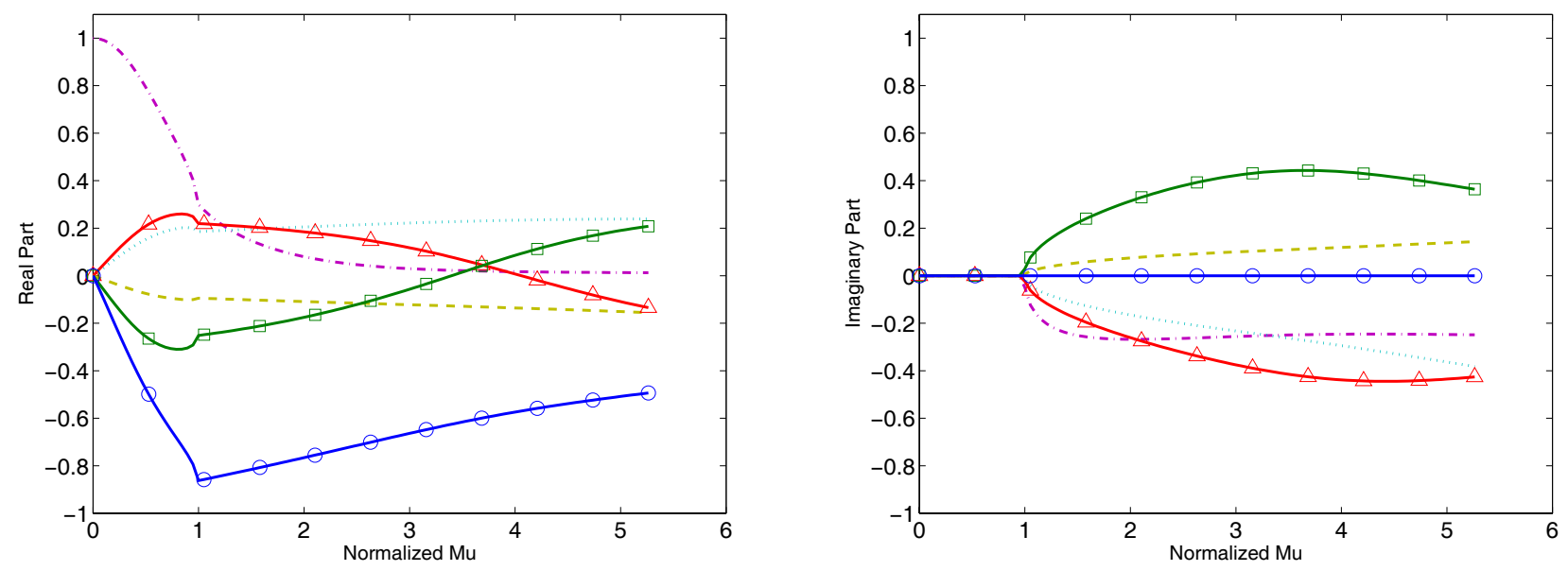

(b)

legend :

Figure 16: Undamped modal participation factors - (a): $M D$ - (b): $M E$

damping may destabilize the system. This point has been investigated by building stability areas with respect to friction and modal dampings. To go further, a metric, referred to as the Robust Damping Factor (RD-Factor), has been used to predict the most stable combination of damping. From a practical point of view, only very low frequency squeals involve two frictionless modes in their coalescence patterns. Higher frequency squeals involve more than two modes and feature far more complicated coalescence patterns. In this case, the effects of damping are all the more complicated to understand. Since the equations governing the system are coupled by friction and by damping, adding damping to a specific mode may alter the behaviour of another one. 


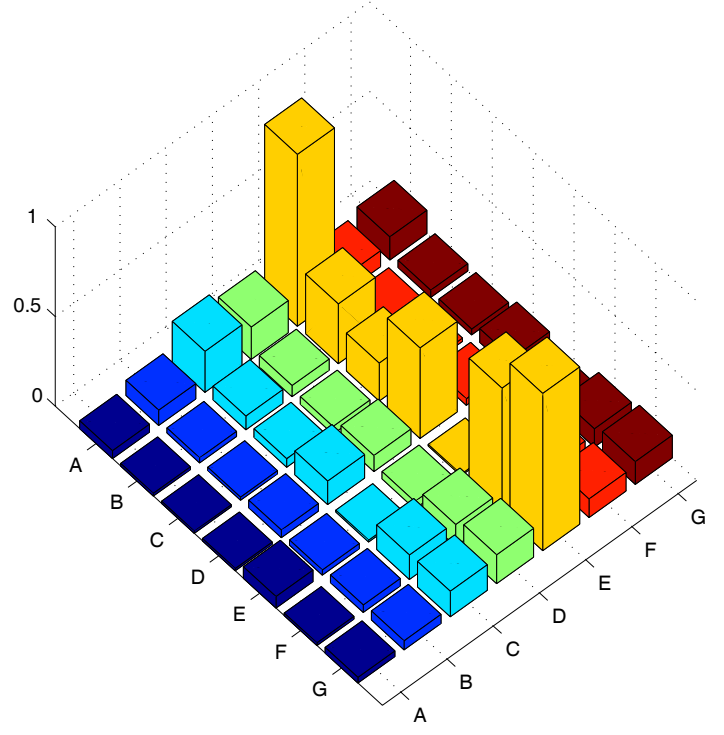

Figure 17: Normalized terms of $\boldsymbol{\Lambda}_{\mathbf{f}}$ for modes $M A$ to $M G$

\section{References}

[1] Kinkaid N.M., O’Reilly O.M., and Papadopoulos P., 2003. "Automotive disc brake squeal". Journal of Sound and Vibration, 267, pp. 105-166.

[2] Chen F., Tan C.A., and Quaglia R.L., 2006. Disc Brake Squeal - Mechanism, Analysis, Evaluation, and Reduction/Prevention. SAE International.

[3] Mahajan S.K., Hu Y.K., and Zhang K., 1999. "Vehicle disc brake squeal simulations and experiences". SAE technical paper 1999-01-1738, Traverse City, Michigan, USA.

[4] Ibrahim R.A., 1994. "Friction-Induced Vibration, Chatter, Squeal, and Chaos. Part 2 : Dynamics and Modeling”. ASME Design Engineering Technical Conferences, 7, pp. 209-2269.

[5] Earles S.W.E., and LeE C.K., 1976. "Instabilities Arising from the Frictional Interaction of a Pin-Disc System Resulting in Noise Generation". Trans. ASME J. Engng Ind., 1, pp. 81-86.

[6] Ouyang H., Mottershead, Cartmell J.E.M.P., and Brookfield D.J., 1999. "Frictioninduced vibration of an elastic slider on a vibrating disc". Journal of Mechanical Sciences, 41(3), pp. 325-336.

[7] Sinou J-J., and JÉZÉQuel L., 2007. "Mode coupling instability in friction induced vibrations and its dependency on system parameters including damping". Journal of European Mechanics A/Solids, 26(1), pp. 106-122. 


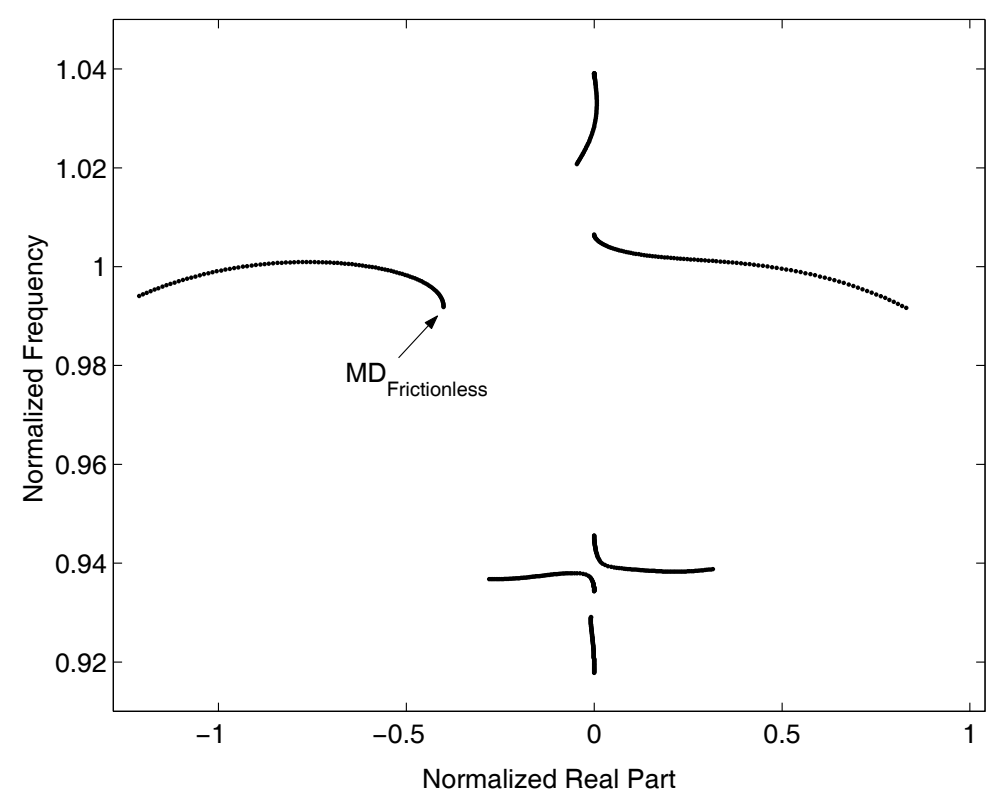

Figure 18: Evolution of the damped eigenvalues in the complex plane - modes MA to MF

[8] Sinou J-J., Thouverez F., and JÉzéquel L., 2003. "Analysis of friction and instability by the center manifold theory for a non-linear sprag-slip model". Journal of Sound and Vibration, 265(3), pp. 527-559.

[9] LILES G.D., 1989. "Analysis of disc brake squeal using finite element methods". SAE technical paper 891150, Traverse City, Michigan, USA.

[10] Kung S.W., Dunlap K.B., and Ballinger R.S., 2000. "Complex eigenvalue analysis for reducing low frequency brake squeal". SAE technical paper 2000-01-0444, Detroit, Michigan, USA.

[11] Chung C.H.J, Steed W., Kobayashi K., and Nakata H., 2001. "A new analysis method for brake squeal part i : Theory for modal domain formulation and stability analysis". SAE technical paper 2001-01-1600, Traverse City, Michigan, USA.

[12] Lee L., Xu K., Malott B., Matsuzaki M., and Lou G., 2002. "A systematic approach to brake squeal simulation using macneal method". SAE technical paper 2002-01-2610, Phoenix, Arizona, USA.

[13] JABER N.A., WANG A.Y., and YAN R., 2006. "Brake noise study (part i) low-frequency squeal". SAE technical paper 2006-01-0474, Detroit, Michigan, USA.

[14] JABER N.A., WANG A.Y., and YAN R., 2006. "Brake noise study (part ii) high-frequency squeal". SAE technical paper 2006-01-0475, Detroit, Michigan, USA.

[15] EARLeS S.W.E., and Chambers P.W., 1987. "Disc brake squeal noise generation: predicting its dependency on system parameters including damping". Int. J. of Vehicle Design, vol. 8, nos 4/5/6, pp. $538-552$. 

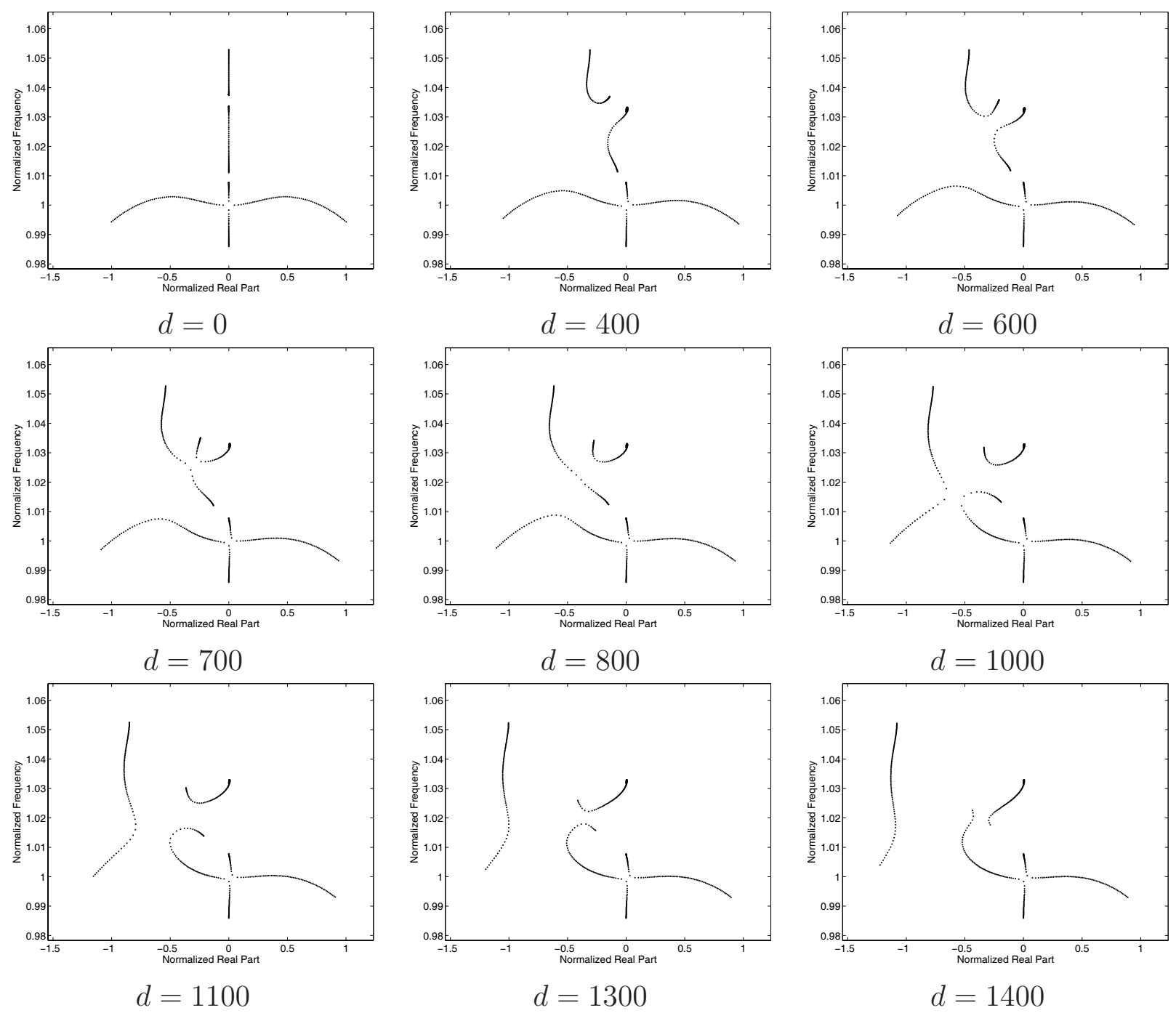

Figure 19: Effect of damping on the damped coalescence patterns

[16] Shin K., OH J-E., and Brennan M.J., 2002. "Nonlinear analysis of friction induced vibrations of a two degree of freedom model for disc brake squeal noise". JSME International Journal, 45, pp. $426-432$.

[17] Shin K., BREnNAn M.J., OH J-E., and HARRis C.J., 2002. "Analysis of disc brake noise using a two-degree-of-freedom model.". Journal of Sound and Vibration, 254, pp. 837-848.

[18] Hoffmann N., and Gaul L., 2003. "Effects of damping on mode-coupling instability in friction induced oscillations". ZAMM $\cdot$ Z. Angew. Math. Mech., 83, No8, p. $524-534$.

[19] FLINT J., 2006. "Complex eigenvalue analysis of friction moment-induced mode coupling in oneand two-dimensional models". In Disc Brake Squeal - Mechanism, Analysis, Evaluation, and Reduction/Prevention. SAE International, ch. 5, pp. 95-130. 
[20] Duffour P., and Woodhouse J., 2004. "Instability of systems with a friction point contact. part 1: basic modelling”. Journal of Sound and Vibration, 271, pp. 365-390.

[21] Massi F., Giannini O., and Baillet L., 2006. "Brake squeal as dynamic instability: an experimental investigation”. Journal of the Acoustical Society of America, 120 (3), pp. 1388-1399.

[22] Kung S.W., SAligrama V.C., and Riehle M.A., 2000. "Modal participation analysis for identifying brake squeal mechanism”. SAE technical paper 2000-01-2764, San Diego, California, USA.

[23] Shi T.S., Dessouki O., Warzecha T., Chang W.K., and Jayaundera A., 2001. "Advances in complex eigenvalue analysis for brake noise". SAE technical paper 2001-01-1603, Traverse City, Michigan, USA.

[24] Bajer A., Belsky V., and Kung S.W., 2004. "The influence of friction-induced damping and nonlinear effects on brake squeal analysis". SAE technical paper 2004-01-2794, Anaheim, California, USA.

[25] Kung S.W., Stelzer G., Belsky V., and BAJER A., 2003. "Brake squeal analysis incorporating contact conditions and other nonlinear effetcs". SAE technical paper 2003-01-3343, Hollywood, Florida, USA.

[26] BAJer A., Belsky V., and Zeng L.J., 2003. "Combining a nonlinear static and complex eigenvalue extraction in brake squeal simulation". SAE technical paper 2003-01-3349, Hollywood, Florida, USA.

[27] FLinT J., 2003. "A review of theories on constrained layer damping and some verification measurements on shim material". SAE technical paper 2003-01-3321, Hollywood, Florida, USA.

[28] Mignery L., WAng J., and Luo J., 2001. "Prediction of damper effects in a brake system model". SAE technical paper 2001-01-3140, New Orleans, Louisiana, USA.

[29] McDaniel J.G., Li X., Elvenkemper A., Wegmann E., Wang W.A., Chen S.E., and Flint J., 2005. "Simulating the effect of insulators in reducing disc brake squeal". SAE technical paper 2005-01-3944, Orlando, Florida, USA.

[30] Huang J., Krousgrill C.M., and Bajaj A.K., 2006. "Modeling of automotive drum brakes for squeal and parameter sensitivity analysis". Journal of Sound and Vibration, 289 (1-2), pp. 245263.

[31] Sinou J-J., Fritz G., and JÉzÉQuel L., 2007. "The role of damping and definition of the robust damping factor (rd-factor) for a self-exciting mechanism with constant friction". Journal of Vibration and Acoustics, 129(3), pp. 297-306.

[32] WiCKeRT J.A., 2006. "Vibration of disc brake rotors". In Disc Brake Squeal - Mechanism, Analysis, Evaluation, and Reduction/Prevention. SAE International, ch. 7, pp. 161-185. 